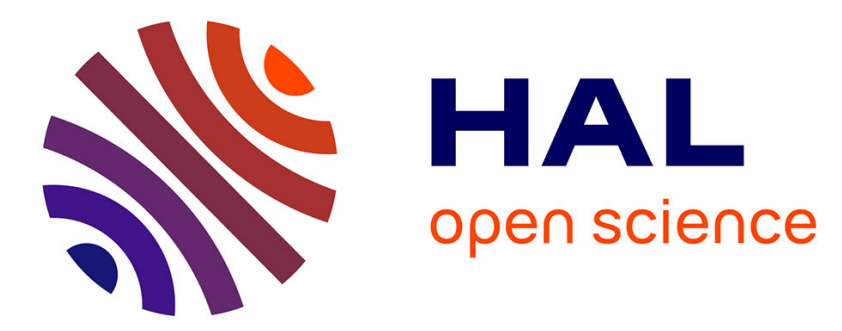

\title{
Spatially Resolved Analysis of an Organic Alkaline RFB to Investigate the Influence of the Operating Conditions
}

Mathilde Cazot, Gaël Maranzana, Jérôme Dillet, Kieran Dale, Sophie Didierjean

\section{- To cite this version:}

Mathilde Cazot, Gaël Maranzana, Jérôme Dillet, Kieran Dale, Sophie Didierjean. Spatially Resolved Analysis of an Organic Alkaline RFB to Investigate the Influence of the Operating Conditions. Journal of The Electrochemical Society, 2020, 167 (10), 10.1149/1945-7111/ab9b94 . hal-02878399

\section{HAL Id: hal-02878399 \\ https://hal.univ-lorraine.fr/hal-02878399}

Submitted on 23 Jun 2020

HAL is a multi-disciplinary open access archive for the deposit and dissemination of scientific research documents, whether they are published or not. The documents may come from teaching and research institutions in France or abroad, or from public or private research centers.
L'archive ouverte pluridisciplinaire HAL, est destinée au dépôt et à la diffusion de documents scientifiques de niveau recherche, publiés ou non, émanant des établissements d'enseignement et de recherche français ou étrangers, des laboratoires publics ou privés. 


\title{
Spatially resolved analysis of an organic alkaline RFB to investigate the influence of the operating conditions
}

\author{
Mathilde Cazot ${ }^{\text {a, b }}$, Gaël Maranzana a ${ }^{\text {, Jérôme Dillet }}{ }^{\text {a }}$, Kieran Dale ${ }^{\text {a }}$, Sophie Didierjean ${ }^{\text {a }}$ \\ a. Université de Lorraine, CNRS, LEMTA, F 54000 Nancy, France \\ b. Kemiwatt, 11 allée de Beaulieu, 35708 Rennes France
}

\begin{abstract}
Designing competitive and reliable Redox Flow Batteries (RFBs) requires the development of specific analytical tools at lab-scale. Specifically, the influence of the cycling conditions on the system performance must be well identified. An instrumented test bench dedicated to the tuning of the operating parameters and the monitoring of the battery internal behavior was developed. The use of a segmented cell with a 1D-like design allowed to focus on the local current distribution along the electrolyte flow. The study started by examining the performances of a RFB coupling the ferri/ferrocyanide couple $\left(\mathrm{Fe}(\mathrm{CN}){ }_{6}^{3-} / \mathrm{Fe}(\mathrm{CN})_{6}{ }^{4-}\right)$ to the anthraquinone Alizarin Red S, over 300 cycles. Once cycling in standard conditions was reviewed, a parameter study was performed to scan a varied range of operating points, by changing the current density, the flow rate and the temperature successively. Thanks to the spatially-resolved analysis of the cell, the global performance could be related to local processes. This investigation gave unprecedented insight of the internal operation of a RFB, with peculiar features appearing at the start of the charge and the discharge. It was shown that a same global response of the cell could actually hide very different internal operations.
\end{abstract}

\section{Introduction}

Redox Flow Batteries (RFBs) are a promising solution for large-scale and low-cost energy storage necessary to foster the use of intermittent renewable sources. Such as any electrochemical reactor, RFBs rely on the reversible conversion of electrical energy into chemical energy. Many research papers about RFBs are already available, many of them dealing with the vanadium technology are based on modeling more than experiments. Due to the complexity of the flow battery systems, experimental tools are required to reach a deep analysis of all the phenomena involved in the operation of the RFB. After having developed an innovative method of symmetric cell to decouple in-situ losses and identify degradation mechanisms during RFB cycling [1], the effort is turned towards in-situ investigations and localized measurements, so that the results directly translate the real-system performance. Local knowledge of the cell performance can also be used for fine model validation and insightful optimization of industrial systems. The analysis of the battery performance is usually based on a single value of the current and of the voltage. These global values are used to calculate the whole battery performance metrics such as the capacity utilization and the voltage, coulombic and system efficiencies. However, additional data are required for deeper analysis of the global results and of the behavior of the cell as they can give new insight of the internal phenomena. Different methods are presented in the literature to obtained local values. Segmented cells have been widely used for fuel cell but they are less common in redox flow batteries studies. Indeed, the technique faces some challenges when implementing it to RFBs: the high electrodes thickness and the conductivity of the electrolyte solutions can induce charge transfer in the inplane direction making the through-plane distribution biased.

Local potential measurements are more developed in the literature of RFBs the local currents. Chen et al. [2] included three potential probes in the form of gold foil located between layers of porous electrodes. These probes allowed to obtain the local value of the porous electrode 
resistance and the authors used it to calculate the average electronic current crossing each layer during polarization experiments. Gandomi et al. [3] used a dynamic hydrogen electrode as a reference electrode to measure local potentials. Four platinum wires probes were placed at the positive side between three carbon papers stacked at both sides, the current collector and the membrane. The reference electrode was placed between two pieces of Nafion ${ }^{\circledR}$ membrane. Cecchetti et al. [4] inserted two hydrogen reference electrodes at the positive and negative electrode, close to the inlet and the outlet of the channels of a VRFB. They measured the influence of the flow rate on the overpotentials and they found that they were higher at the negative electrode and that the difference between the inlet and the outlet was small. During cycling, the local potentials revealed that the positive electrolyte deviated towards higher state of charge values, while the negative state of charge at the end of the charge decreased. Bhattarai et al. [5] and Ghimire et al. [6] built a segmented cell with a collector and a porous electrode composed of 16 isolated segments. The cell operated in galvanostatic mode by controlling each segment independently the individual potentials were recorded. This set-up remains imperfect as the potential difference induced by the monitoring of each segment could give rise to internal current that are comparable to the internal shunt currents.

While the local potentials are usually measured through the porous electrodes, the local current are preferably probed along the flow of the electrolytes, and several methods have been tested, as reviewed by Gandomi et al [7]. Access to the locally-resolved current distribution requires the measurement of the real through-plane component generated within the cell, without disturbing the cell operation. As it was numerically demonstrated by Eckl et al. [8] in the case of fuel cells, lateral current spread can be substantial if the solid plate behind the electrode is not segmented. Hsieh et al. [9] confirmed this experimentally in the case of a VRFB by comparing the probed local current with a segmented current collector associated with or without full segmentation of the end plates. They divided the negative collector of a $100 \mathrm{~cm}^{2}$ cell in 25 segments, each being connected to a $50 \mathrm{~m} \Omega$ shunt resistance. They showed that the cell design had an influence on the results due to the current spreading through the flow plate and due to the contact resistances, which are not equal because of the non-uniform compression of the segments. The accurate estimation of internal current must go along with the segmentation of the solid plates constituting the back of the cell. The presence of conductive liquid electrolytes also questions the need to extend the segmentation to the porous electrode to overcome current spreading laterally, through the liquid phase. Bhattarai et al. [5] were the first ones to implement the porous electrode segmentation in a RFB. They concluded that the result was only slightly improved resolution with electrode segmentation. Apart from this gain, the electrode segmentation is difficult to execute and affects the internal porous structure. For these reasons, this option was not considered in this study. Since the current applied on one side crosses the entire cell, it is sufficient to segment only one of the current collectors. For the same reason, the choice of the side used for the localized measurements does not affect the current [10]. Clement et al. [10] obtained current maps by segmenting a square cell and they demonstrated that charging the VRFB was not limited by mass transport but rather by the electrochemical window of the redox couple. They studied the influence of the parameters related to the flow: flow rate, thickness, porosity and wettability of the porous electrodes.

The through-plane distribution of current can be collected by several ways. The four most common techniques described in the literature are the resistor network, the printed circuit board, the Hall effect sensors and the potential probes. With a network of shunt resistors, the local current value is deduced from the potential drop across small resistors. The latter must be smaller than the internal resistance of the set-up, to be able to detect the whole current component. This configuration allows local EIS characterization, but necessitates to minimize 
the contact resistances for good accuracy and low impact on the cell performance. Similarly, a network of Hall-effect sensors can be placed behind the current collector. The magnetic induction through the sensors provides accurate estimation but is applicable only over a low range of current. The sensors also induce a voltage offset that can fluctuate with temperature. It has so far never been applied to flow battery studies. Both shunts and Hall sensors require the individual wiring of each segment and are thus cumbersome. Printed Circuit Boards (PCBs) can be a good alternative in terms of spatial resolution. For instance, the company $\mathrm{S}++{ }^{\circledR}$ is wellknown in the fuel cell research and industry for its off-the-shelf PCB products. Thanks to low hardware requirement, these devices are meant to be non-intrusive and easily integrated to battery stacks. Nevertheless, this advantage is not really valid since the full segmentation of the end plate was deemed necessary to probe the internal current accurately [9]. For that reason, PCB tests reported in the literature are made with segmented set-ups. These three methods of shunt resistors, Hall-effect sensors and PCB require the segmentation of the end plate, which entails underlying challenges: the appropriate method of segmentation to get a plane slab and local uniform compression, the selection of insulating material that must be compatible and robust, the minimization of contact resistances between the segments and the hardware at the back.

The development of an instrumented test bench for full cell experiments to investigate the local phenomena and get a spatial resolution of the current is presented in the next section. This tool was used to perform a fine parameter study by varying alternatively the current, the flow rate and the temperature. The effect of each parameter on the battery heterogeneity are compared and conclusions are drawn.

\section{Experimental}

Segmented cell and test bench. The segmented cell used in this work had a flow-through design. The active surface of the segmented cell was $30 \mathrm{~cm}$ long and $1.4 \mathrm{~cm}$ wide, giving an area of $S=42 \mathrm{~cm}^{2}$. This cell length corresponds to the height of a typical RFB stack developed at the industrial scale. The essentially-1D geometrical surface ensured that local variables could be tracked along the flow inside the cell and prevented from facing flow distribution issues. Figure 1 gathers the successive layers used to assemble the set-up, from left to right.
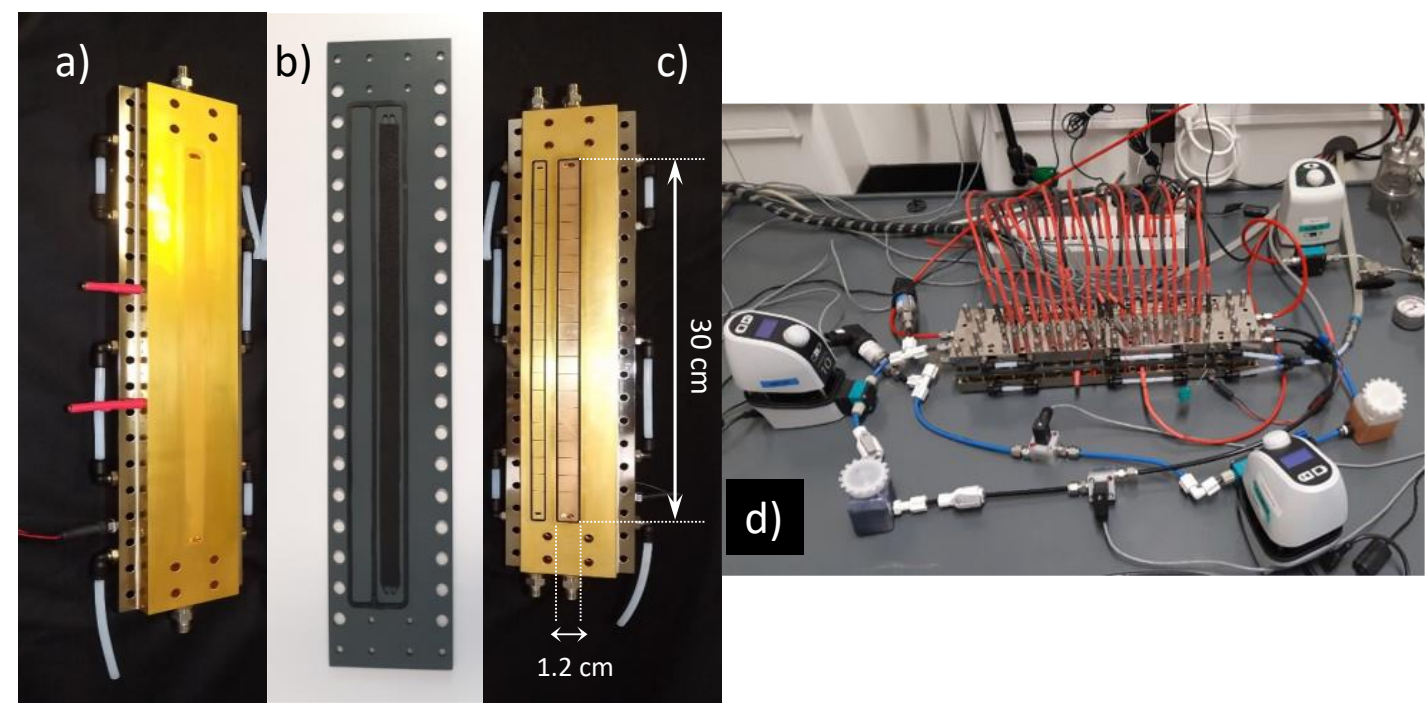

Figure 1. a, b, c) Exploded view of the layers constituting the segmented cell assembly. d) Global view of the test bench with the wired cell. 
The non-segmented current collector (Figure 1a) was a $15 \mathrm{~mm}$ brass plate covered with a layer of Nickel and then gilded with a $3.5 \mu \mathrm{m}$ layer. The Ni-coat shields it from corrosion while the thin gold leaf brings a good electrical contact with the graphite electrode. It was fastened on the back to a Nickel-coated brass clamping plate that contained the hydraulic circuit for the thermal cell control and would hold the assembly tight. These two slabs had a high thermal conductivity to facilitate the thermal regulation. A thin Kapton ${ }^{\circledR}$ tape ensuring electrical isolation separated them. The PVC frame (Figure 1b) topped the first block and held the graphite electrode. The porous electrodes were fed in flow-through configuration, by two small manifolds $(5 \mathrm{~mm}$ long and $2.5 \mathrm{~mm}$ thick) machined in the PVC frame on both edges of the electrode. The third layer was the membrane (not presented in the figure). The frame supporting the other electrode was identical to the first one (Figure 1b). The current collector at the negative side (Figure 1c) had its active surface divided into 20 segments of $2.1 \mathrm{~cm}^{2}$ each. They were machined in the brass slab and then surrounded with an epoxy resin that insulated them one from the other and from the surrounding block. These elements were assembled and tightened with a torque screwdriver to $1 \mathrm{Nm}$. This design has stemmed from many years of in-house developments and successive generations of segmented cells [11]. A $5 \mathrm{~m} \Omega$ resistor was connected to each segment and the potential drop at the resistor was amplified by a factor of 500 before being recorded.

The cell was then connected to a fully instrumented test bed, as illustrated in Figure 1d. The two sides of the cell were supplied by parallel co-flows of electrolyte and the segments were numbered 1 to 20 from the flow inlet. Diaphragm pumps were used to provide flow rate between 10 and $100 \mathrm{~mL} \mathrm{~min}^{-1}$. A flowmeter was installed in each hydraulic circuit to verify the flow rate delivered by the pump. The temperature-control bath generated a flow of water through the serpentine channels of the cell external slabs. A LabVIEW control software developed at the laboratory was used to manage the experimental facility. The cycling and characterization steps were defined on the computer interface along with the operating conditions: pumping power, cell temperature and electrical power supply. The cell and the auxiliary devices were controlled in real time during operation. The platform collected the global and local electrical data but also the flow rate in each electrolyte flow path.

Materials: membrane, porous electrodes, electrolytes. The separator used was a $80 \mu \mathrm{m}$ Aquivion ${ }^{\circledR}$ cation exchange membrane (E98-09S Solvay) made of PerfluoroSulfonic Acid (PFSA) polymers. It was pretreated by boiling the polymer in a solution of HNO3 $1 \mathrm{M}$ at a temperature of $130^{\circ} \mathrm{C}$ for 2 hours. This step made more ionic sites functional and cleaned the separator. After cooling down, the polymer membrane was rinsed into baths of deionized water until the solution reached $\mathrm{pH} 7$ in order to eliminate the remaining acid. The protons were finally exchanged to potassium ions by soaking the membrane into 2 baths of $1 \mathrm{M} \mathrm{KOH}$. It was ready for use in alkaline conditions and was stored in $\mathrm{KOH}$ until assembled wet in the cell.

The electrode material was a GFD porous graphite felt from SGL Carbon Group (reference GFD 4.6 EA), $4.6 \mathrm{~mm}$ thick, made from a base of polyacrylonitrile fibers successively carbonized and graphitized, and it was compressed to $35 \%$ in the cell. The catholyte was an alkaline solution of $0.5 \mathrm{M}$ of potassium ferrocyanide $\mathrm{K}_{4} \mathrm{FeCN}_{6}$ mixed with $0.2 \mathrm{M} \mathrm{NaOH}$ and the anolyte contained the 3,4-Dihydroxy-9,10-anthraquinone-2-sulfonic acid or Alizarin Red S (noted ARS), pertaining to the anthraquinone group of organic molecules that exchange 2 electrons per molecule. Their interest for flow batteries have been reported previously [12, 13, 14], as they are abundant and can be low-cost, without the detrimental footprint of extracted materials (such as vanadium, zinc...). The oxidized form of ARS was dissolved at a concentration of $0.2 \mathrm{M}$ in $1.2 \mathrm{M} \mathrm{KOH}$. Both electrolytes had a $\mathrm{pH}$ around 13.5. Anthraquinones 
being known to be sensitive to oxygen, the hydraulic circuit of the anolyte was purged with nitrogen during 20 minutes while the solution was flowing into the cell, to eliminate risk of spontaneous oxidation of the reduced form once the anolyte was charged. The catholyte being sensitive to light, its tank was wrapped in foil to protect it from light. Both electrolytes were initially at discharged state. The standard volume used for the tests were $100 \mathrm{~mL}$ of each solution. Therefore, the capacity-limiting side was the anolyte (due to its lower electron concentration of $0.4 \mathrm{M}$ ), with an excess of $20 \%$ capacity in the catholyte. This configuration ensured that the cell was cycled on the total capacity of the anolyte, which eased the interpretation of the results, as already shown in previous papers [15]. As such, the State of Charge (SoC) of the battery corresponded to the SoC of the anolyte. With this set-up configuration and the electrode porosity being $90 \%$, the tank-to-electrode volume ratio was 9 .

Electrochemical analysis. The two electrolytes were characterized by cyclic voltammetry before and after a battery cycling, at a voltage scan rate of $100 \mathrm{mV} \mathrm{s}^{-1}$. The electrochemical cell was composed of a glassy carbon working electrode (surface of $0.07 \mathrm{~cm}^{2}$ ), a platinum wire as counter-electrode and an $\mathrm{Ag} / \mathrm{AgCl}$ reference electrode.

Operating parameters during battery cycling. In this study, the impact of three operating parameters on the battery response was addressed: the average current density $J$, the temperature $T$ and the flow rate $\dot{q}$. They were varied one at a time, the others being maintained to their standard values: the standard average current density was $40 \mathrm{~mA} \mathrm{~cm}{ }^{-2}$, the standard temperature was $25^{\circ} \mathrm{C}$ and the standard flow rate was $100 \mathrm{~mL} \mathrm{~min}^{-1}$. A safety cell voltage window of $[0.6 \mathrm{~V}-1.5 \mathrm{~V}]$ was defined to prevent side reactions (such as oxidation of the anthraquinones, water-splitting reaction) and degradation of the electrolytes. $J, \dot{q}$ and $T$ were modified in the range given in Table I.

\section{Table I. Design of experiment for the parameters study}

\begin{tabular}{|c|c|c|}
\hline Test description & Scanned parameter range & Fixed parameters \\
\hline $\begin{array}{l}\text { Varying average current } \\
\text { density }\end{array}$ & $\begin{array}{l}10 \leq J \leq 150 \mathrm{~mA} \mathrm{~cm}^{-2} \\
\text { In absolute value }\end{array}$ & $\begin{array}{l}\dot{q}=10,50 \text { or } 100 \mathrm{~mL} \mathrm{~min}^{-1} \\
T=25^{\circ} \mathrm{C}\end{array}$ \\
\hline Varying flow rate & $10 \leq \dot{q} \leq 100 \mathrm{~mL} \mathrm{~min}^{-1}$ & $\begin{array}{l}J=40 \mathrm{~mA} \mathrm{~cm}{ }^{-2} \\
T=25^{\circ} \mathrm{C}\end{array}$ \\
\hline Varying temperature & $10 \leq T \leq 40^{\circ} \mathrm{C}$ & $\begin{array}{l}J=40 \mathrm{~mA} \mathrm{~cm}^{-2} \\
\dot{q}=100 \mathrm{~mL} \mathrm{~min}^{-1}\end{array}$ \\
\hline
\end{tabular}

As it was discussed by Nemani and Smith [16], it is important to compare the actual flow rate to the stoichiometric value, noted $\dot{q}_{F}$. The flow factor or stoichiometric coefficient $F F$ is the ratio between the electrolyte flow rate $\dot{q}$ and $\dot{q}_{F}$ :

$\dot{q}_{F}$ being defined as:

$$
F F=\frac{\dot{q}}{\dot{q}_{F}}
$$

$$
\dot{q}_{F}=\frac{J S}{z F C_{\text {reactant }}}
$$


$S$ is the geometric electrode area and $C_{\text {reactant }}$ the concentration at the initial state. For the standard average current density of $40 \mathrm{~mA} \mathrm{~cm}{ }^{-2}$, the stoichiometric flow rate is $2.6 \mathrm{~mL} \mathrm{~min}^{-1}$, which gives $F F=38.4$ when operating at the standard flow rate $100 \mathrm{~mL} \mathrm{~min}^{-1}$.

The results were also analyzed considering the energy efficiency $E E$ :

$$
E E=\frac{\int_{0}^{t_{c h}} I(t) U_{c h}(t) d t}{\int_{0}^{t_{d i s c h}} I(t) U_{\text {disch }}(t) d t}
$$

By operating in galvanostatic mode, the energy efficiency allows to compare the voltage during charge $U_{c h}$ and discharge $U_{\text {disch }}$ and thus to evaluate the influence of the operating parameters on the potential limitations.

Cycling procedure and experimental methods. The basic procedure was to charge and discharge the cell at constant average current density, and to record the voltage response of the battery over time. A small rest of $60 \mathrm{~s}$ was executed at the end of the charge and discharge to avoid abrupt changes of the current flow. Before performing the parameter study, the cell was run for 50 cycles in standard conditions to stabilize it. 10 cycles were executed at each set of parameters, and the record of the 10th cycle was selected for analysis. Due to the aging of the materials (especially the anolyte species as described in the Result section) and since all the tests were performed on the same cell, 4 cycles in standard conditions were inserted between each operating value tested to follow the evolution of the performances in standard conditions. These high flow rate cycles permitted to recover all the capacity available in the anolyte within the voltage window, by boosting active species supply. From this accessible capacity could be defined the SoC of the anolyte. Then, a polarization curve (PC) was performed for each parameter, with 2 full standard cycles between each PC to reset the battery. The characterization was repeated for three values of the SoC: 20,50 and $80 \%$. The cell was set at the desired SoC according to the total capacity achieved in the preceding cycle in standard conditions corresponding to $100 \% \mathrm{SoC}$ of the anolyte.

Polarization curve measurement method. Different procedures exist in the literature to build the polarization curve (PC) of a battery. The analysis of the $\mathrm{PC}$ requires maintaining the SoC constant. In this study the average current density was varied in the form of a temporal ramp of rate $0.2 \mathrm{~A} \mathrm{~s}^{-1}$. Figure 2 depicts the protocol used. In this figure, the cell was first discharged until the low voltage cut-off $(0.6 \mathrm{~V})$ was reached and the corresponding lowest current value $\left(-J_{1}\right)$ was memorized. Then the ramp was reversed to reach zero, and the exact opposite triangle signal until $J_{1}$ was applied to return the cell to its initial SoC. After a period of rest $\Delta t_{\text {rest }}$ of 2 minutes allowing to restore uniform electrolyte concentrations inside the cell, the protocol was repeated in the other direction to get the positive part of the PC. In this second stage, the maximum current depends on the upper voltage limit $(1.5 \mathrm{~V})$ and thus can be different than in the first stage. The bold parts of the curves in Figure 2 represent the data used to construct the PC. 


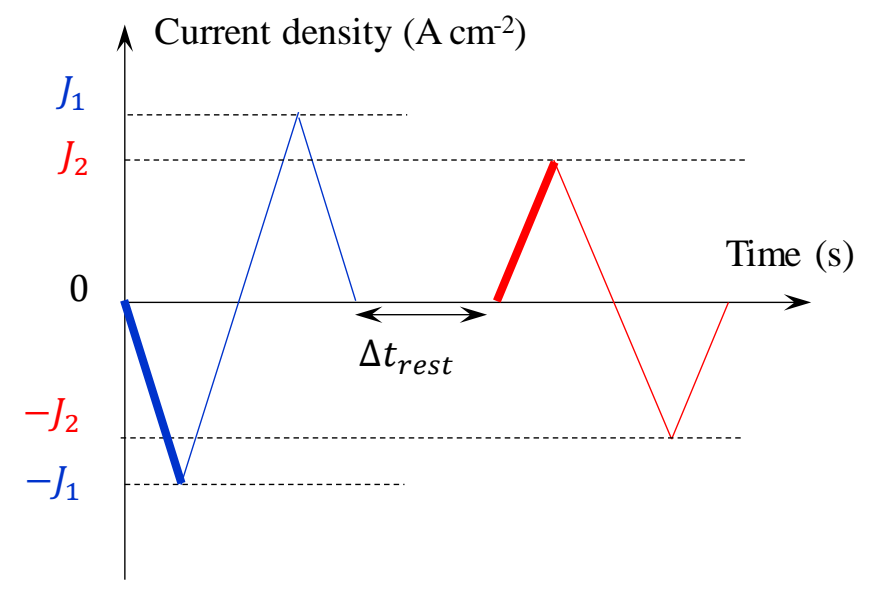

Figure 2. Ramp method for a polarization curve acquisition. The charge and discharge are performed with the same current scan rate of $0.2 \mathrm{~A} \mathrm{~s}^{-1}$. The bold parts are used to construct the PC.

Thanks to the segmented cell, the local PCs can be obtained by plotting $U_{c e l l}$ as function of the local current density. This assumes that the potential of the current collector is uniform which is coherent with the high conductivity of the solid phase.

\section{Results and discussion}

The following results capture the interest of using an instrumented test bench and segmented cell to comprehend all the implications from a complex system such as the RFB. The evolution with cycling of the monitored global and local parameters are given, before examining the PC results. The segment number $k$ is referred as Seg\#k and its local PC as PC\#k.

Cycling in Standard conditions. Figure 3a displays the charging and discharging curves of cycles 1, 10, 50, 100, 200 and 300. The initial cycles (1 to 10) are smooth, with a regular voltage variation. Nevertheless, starting from cycle 10, their shape rapidly evolves into several waves, indicating a rapid chemical modification which stabilizes after cycle 100. The first section of the charge gradually decreases in potential to make a first wave (also called a plateau) appear between 0 and $40 \%$; from $40 \%$ to $100 \%$ the voltage in charge is kept unchanged with cycling. What happens early in charge corresponds to the last half of the discharge: between 45 and $100 \%$, the discharge curves drop towards lower potentials to delineate another wave of increasing significance. A third small modification of the shape of the discharge curve appears with aging in the last $10 \%$ of discharge. 

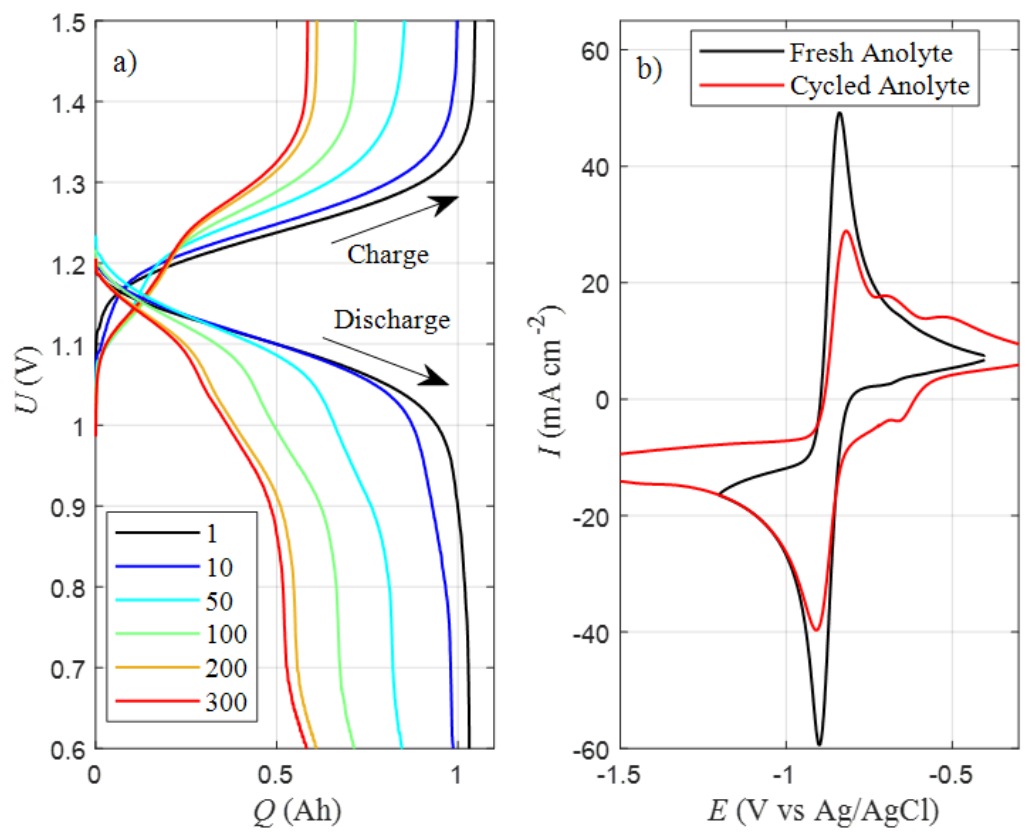

Figure 3. a) Charge/Discharge profiles for cycles 1, 10, 50, 100, 200 and $300 . J=40 \mathrm{~mA} \mathrm{~cm}^{-2}$, $\dot{q}=100 \mathrm{~mL} \mathrm{~min}^{-1}, F F=38.4$ and $T=25^{\circ} \mathrm{C}$. b) Cyclic voltammograms of the freshly prepared anolyte and after 300 cycles in the battery

The appearance of such peculiar features is the signature of successive electrochemical reactions during charge or discharge of the electrolytes. Thanks to a preliminary half-cell study presented in a previous paper [1], these occurrences cannot be attributed to the catholyte that is very stable during cycling. An electrochemical analysis of the electrolytes was carried out before and after cycling to confirm it. While the cyclic voltammogram of the catholyte was kept unchanged, the anolyte (Figure $3 \mathrm{~b}$ ) revealed that the initial active species (formal redox potential $E^{0 \prime}=-0.87 \mathrm{~V}$ ) was unstable and partially transformed into two other electrochemical systems at higher potentials $\left(E^{0 \prime}=-0.7 \mathrm{~V}\right.$ and $\left.-0.55 \mathrm{~V}\right)$. These new subsidiary reactions tally with the new waves observed on the voltage profiles of the battery on Figure $3 \mathrm{a}$.

The evolution of the voltage profiles goes along with significant capacity decay that stabilize after cycle 200. This loss is also visible on the anolyte voltammograms, as the peaks intensities dropped with aging and are not counterbalanced by the height of the new peaks. The anolyte molecules instability requires to regularly run high flow rate standard cycles (as described in the method section) to keep track of the total capacity available in the anolyte.

Whatever the aging, the monitoring of local currents reveals a non-uniform distribution during charge-discharge phases. Figure 4 gives the absolute value of the local current density records for cycle 10 (Figure 4a, 4b and 4c) and 100 (figure 4d). In Figure 4a and 4d, the black vertical line delimits the charge (on the left) and the discharge steps (on the right); the rest period (60 s, no current) between charge and discharge is not represented. The curves are plotted versus cumulative capacity $Q$ of a full cycle (charge + discharge) in Ah. 

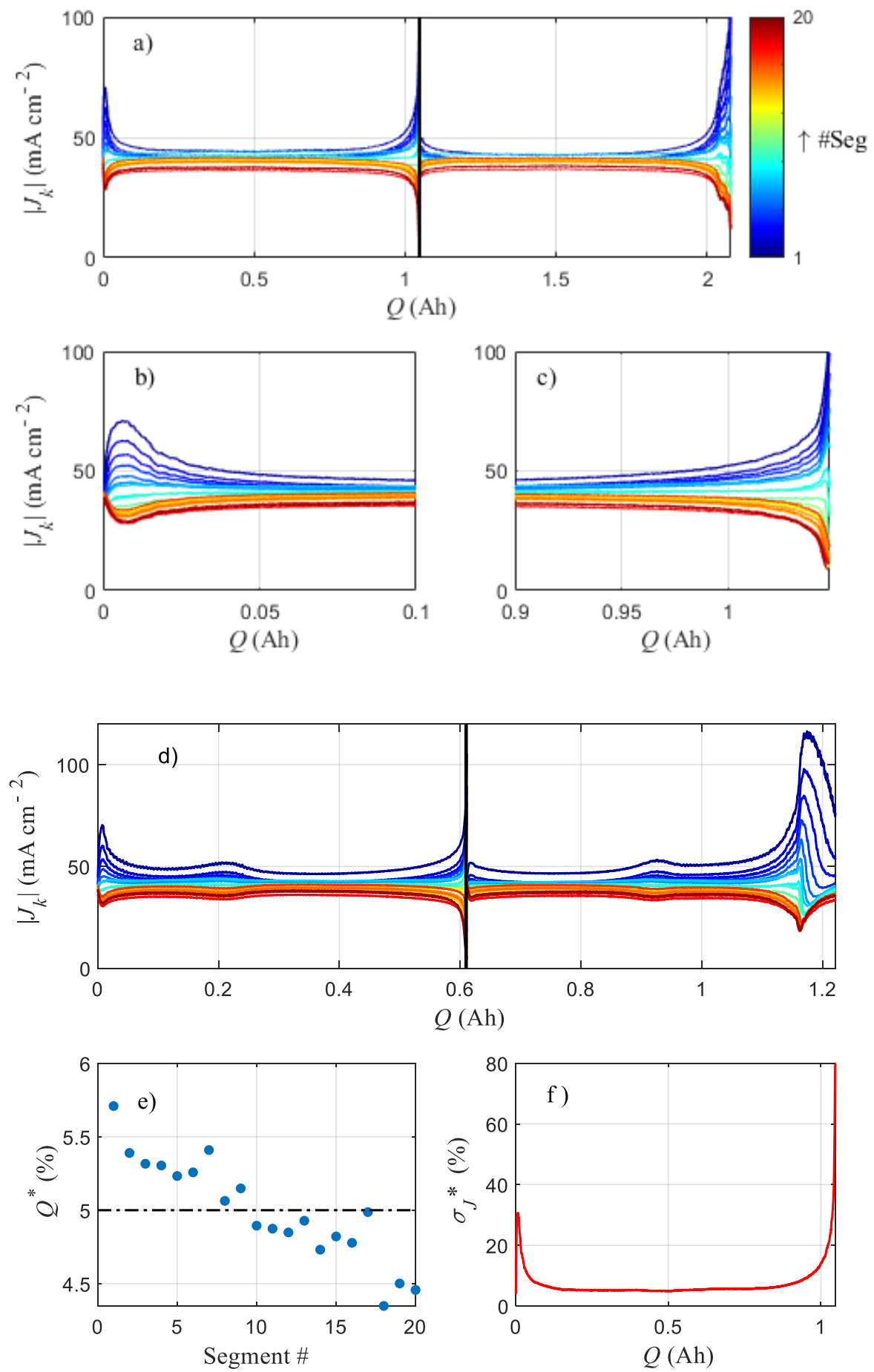

Figure 4. Absolute value of the local current density $\left|J_{k}\right|$ of the segmented cell as a function of the cumulative capacity of a full cycle, $J=40 \mathrm{~mA} \mathrm{~cm}{ }^{-2}, \dot{q}=100 \mathrm{~mL} \mathrm{~min}^{-1}, F F=38.4$ and $T=25^{\circ} \mathrm{C}$. a) Cycle 10, b) Zoom of the first 5\% of the charge of cycle 10, c) Zoom of the last $5 \%$ of the charge of cycle 10, d) Cycle 200, e) Distribution of the local capacity during charge, black dashed line gives the theoretical uniform local capacity, f) Normalized standard deviation of the local current as a function of the capacity.

The charge and discharge in Figure $4 \mathrm{a}$ and $4 \mathrm{~d}$ essentially present the same pattern. For every cycle, the current distribution features significant fluctuations around the average value of $40 \mathrm{~mA} \mathrm{~cm}{ }^{-2}$. The inlet segments (in blue) are always above the average while the outer 
segments (in orange/red color) exhibit lower values. The first and last segment feature respectively the highest and lowest current at any time. The local current density in the center of the cell (light blue/green curves) is almost constant and close to the average value. Hsieh et al. [9] also reported these phenomena in VFB. The start and end of charge of cycle 10 are zoomed in for better view in Figure $4 \mathrm{~b}$ and $4 \mathrm{c}$. Starting at the same value, the local current densities exhibit a hump during the first $5 \%$ of the step. The most important spike magnitudes are visible for Seg\#1 and Seg\#20 with an opposite shape, as the sum of all local currents is held constant. Afterwards, the current distribution evolves to be almost uniform during most of the charge and discharge phases. The end of the charge or discharge is marked by a stark rise of current at the inlet and decrease at the outlet. These transient responses, where the inlet segments produce or consume more charge than the outlet ones, are speculated to derive from the local concentration gradient along the electrode channel, produced by two distinctive effects.

At the beginning of charge or discharge, when the current is applied, all the segments contain the same reactant concentration so that they deliver the same amount of charges (indeed all the curves of Figure $4 \mathrm{~b}$ start from the same point). As long as the SoC in the tank remains close to $0 \%$ or $100 \%$, the Nernst potential at the inlet is very high allowing a large faradaic production of charges while at the same time, the outer segments are fed by the depleted electrolyte that already reacted along the channel, thus having a lower Nernst potential. Because the total current is kept constant, the spatial variation of the Nernst potential could certainly explain the trend observed in Figure 4b. After a few percent of charge or discharge, the heterogeneity would mitigate (since the Nernst potential has a logarithmic dependence on the SoC) and the internal operation would reach a steady state where the inlet segments keep a superior current value than the last segments for local concentration reason. At the end of the process, an equivalent mechanism could derive from the decreasing concentration of active species. The outer segments would suffer from a reactant depletion first and could no longer sustain the reaction rate; the local current at the inlet in turn would increase abruptly to comply with the global current applied to the battery. This critical heterogeneity might induce a concentration overpotential, which cumulates with the Nernst potential so that the cell voltage reaches the cut-off voltage, and the process stops. These conjectures need to be supported by a dynamic modelling of the electrochemical reactions distribution along the cell to be validated. As depicted in Figure 4d presenting the cycle 100, the patterns at start and end of each process are globally conserved throughout the cycling. However, due to the anolyte electrochemical evolution, a second spike rises during the charge and the discharge whose position evolves during cycling. At the very end of the discharge, a secondary reaction starting at low potentials mitigates back the heterogeneity during the last few percent of the discharge. The segmentation of the RFB cell forces to reassess the standard way of analyzing the battery response. Given that the current distribution varies at each time step and differently with the conditions as presented in the next sections, the data must be regarded more globally to deduce a general trend of variation. To this end, two macroscopic parameters were introduced:

The first measure is local but covers the full stage: it is the local capacity percentage of the segment number $k$ noted $Q_{k}^{*}$, and is calculated as a fraction of the total accessed capacity according to:

$$
Q_{k}^{*}=\frac{1}{Q} \int_{0}^{t_{\max }} J_{k}(t) d t
$$


With $Q$ the total capacity of the cell, accessed during charge or discharge:

$$
Q=\int_{0}^{t_{\max }} J(t) d t
$$

The second measure is instantaneous: the internal current distribution at a time step is characterized by its standard deviation. It is defined in a non-dimensional form as:

$$
\sigma_{J}^{*}(t)=\frac{1}{\bar{J}} \sqrt{\frac{1}{20-1} \sum_{k=1}^{20}\left(J_{k}(t)-\bar{J}\right)^{2}}
$$

With $\bar{J}$ the average value of the average current density imposed by the load. $\sigma_{J}^{*}$ will either be given as a function of the capacity during cycling or of the average current density during PC. Using the local current distribution in charge presented in Figure $4 \mathrm{a}$, these two criteria are depicted in Figures $4 \mathrm{e}$ and $4 \mathrm{f}$. The same was calculated for discharge but is not presented here. The dashed line in Figure 4e embodies the ideal case of uniform local capacity. The data points deviation from this level highlights the non-uniformity. The first segment delivered $20 \%$ as much capacity as the last one. The same occurred in discharge. It means that the cell is on average always overloaded at the inlet. In Figure 4f, the local current distribution clearly shows two zones of important heterogeneity at start and end of the charge. The same occurred in discharge. Both charge and discharge are scrutinized in the next sections for different operating conditions.

Global and local PC in standard conditions and various SoC. Figure 5a presents the global PCs at SoC $20 \%, 50 \%$ and $80 \%$ obtained after the 150th cycle (that is when the modification of the anolyte electrochemical behavior was stabilized).
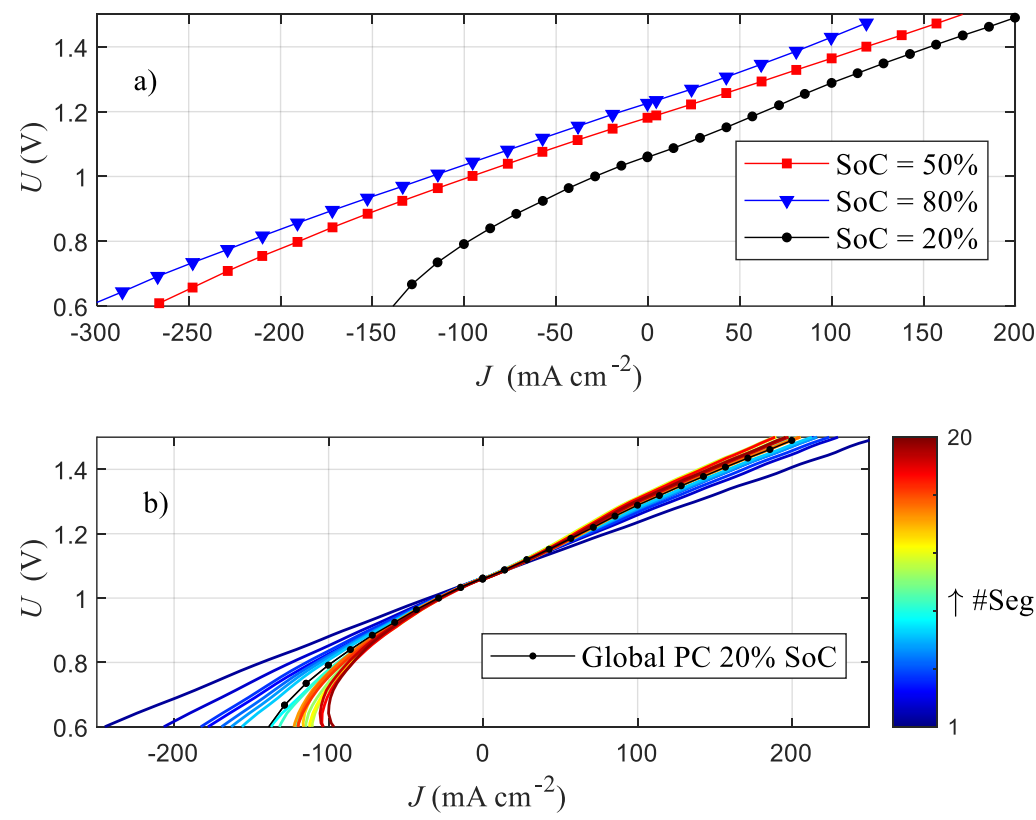

Figure 5. a) Global polarization curves at 20, 50 and $80 \%$ SoC, after cycle 150, b) Local polarization curves at $20 \%$ SoC. The global PC is represented by black dots. $\dot{q}=100 \mathrm{~mL} \mathrm{~min}^{-1}$ and $T=25^{\circ} \mathrm{C}$.

As expected, the PCs are shifted upwards at higher SoC, because the Open Circuit Voltage (OCV), given by the Nernst law, increases. However, the PCs at SoC $20 \%$ and $80 \%$ are not 
perfectly symmetrical with respect to the $\mathrm{PC}$ at $\mathrm{SoC} 50 \%$. This can be caused by the nonsymmetrical SoC of both electrolytes, as the anolyte is the capacity-limiting side and suffers from capacity degradation with cycling. As the voltage boundaries are not centered around the $\mathrm{OCV}$, the $\mathrm{PC}$ at $50 \%$ SoC is not perfectly symmetrical with respect to 0 and larger currents are reached in discharge than in charge. Nevertheless, this PC is almost linear between -200 to 200 $\mathrm{mA} \mathrm{cm}{ }^{-2}$ with a slope equal to $1.97 \Omega \mathrm{cm}^{2}$ (obtained by curve fitting), and it shows a small bend at higher discharge rates. This equivalent resistance depicts the sum of activation, ohmic and mass transport losses of the system at this SoC. When the battery is almost discharged at SoC $20 \%$, its characteristic is bent in the negative polarization from $-50 \mathrm{~mA} \mathrm{~cm}{ }^{-2}$. Indeed, a low material concentration is available for discharge and this lack of reactant establishes a concentration overpotential. In the positive region, the plot is essentially linear. At $80 \%$ SoC, the characteristic curve is nearly parallel to the $\mathrm{PC}$ at half-charge while featuring a non-linear part at highly positive currents (from approximately $80 \mathrm{~mA} \mathrm{~cm}$ ) for the same reasons as at SoC 20\%; the deviation is nevertheless less marked. Due to the high SoC, a large amount of reactant is available for discharge and the $\mathrm{PC}$ seems linear until the maximum average current density is reached. The use of a segmented cell enables plotting the local PCs, by representing cell voltage versus the current density of each segment. The 20 curves at SoC $20 \%$ are compared in Figure 5b along with the global PC (black dots). The local PC highly depends on the position along the length of the cell, and the global PC perfectly matches with the PCs of the center segments. As expected, the contribution of all segments influences the cell response that is approximately the average of the local curves. Seg\#1 displays a perfectly linear PC: the inlet never suffers from active material starvation, showing a purely resistive behavior.

From Seg\#2, a region assigned to mass-transport limitation appears at highly negative polarization, and its significance grows with the position in the electrode channel: this stems from the accumulation of reactant consumption along the cell. Similar localized polarization curves have been reported by Becker et al. [17]. These authors also highlighted reactant starvation close to the cell outlet during a PC. In figure 5b, the effect of the concentration effects are emphasized by the low SoC: large concentration over potentials related to active species starvation appear at negative polarization while they remains very low in the positive part.

In the three subsequent parts, the impacts of the parameters $J, \dot{q}$ and $T$ on the battery response are evaluated one at a time. The final section seeks the optimization of a battery cycle in light of the preceding learnings.

Influence of the average current density. The average current density was scanned from 10 to $150 \mathrm{~mA} \mathrm{~cm}^{-2}$, while the flow rate and the temperature were set to their standard value $\left(100 \mathrm{~mL} \mathrm{~min}^{-1}, 25^{\circ} \mathrm{C}\right)$. Its impact on the battery cycles is given in Figure 6, by comparing the voltage curves in charge and discharge and showing the energy efficiency. 

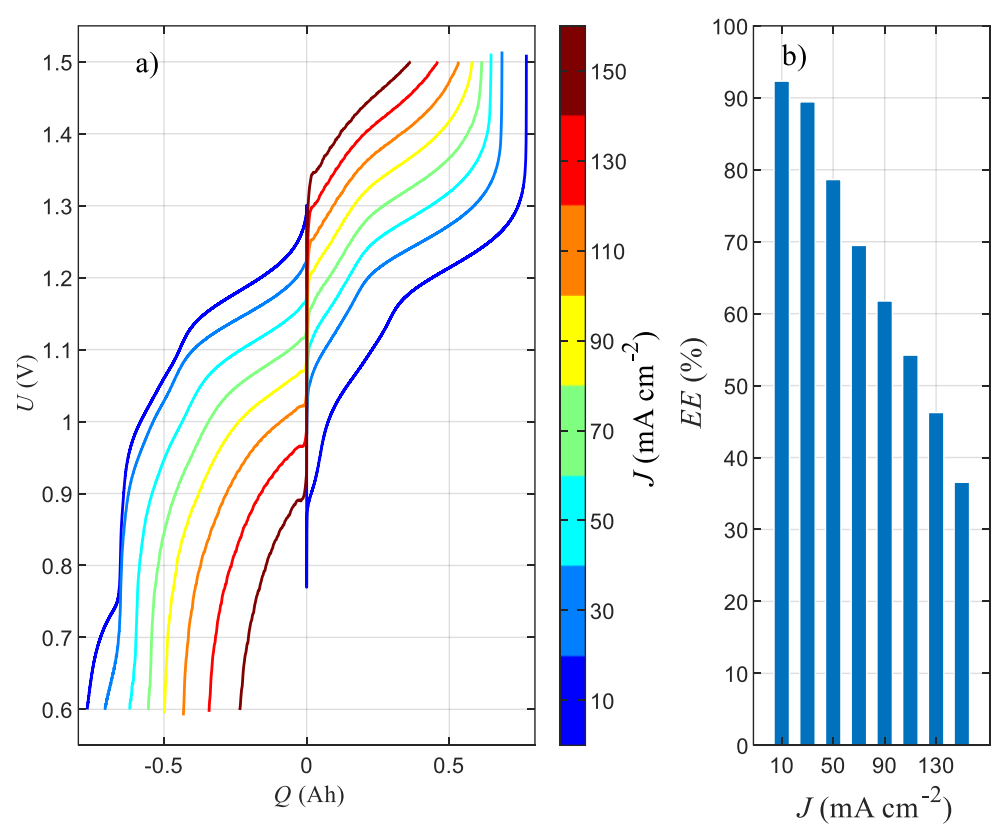

Figure 6. a) Voltage charge and discharge curves as a function of the capacity (positive in charge, negative in discharge) for all the currents tested, $\dot{q}=100 \mathrm{~mL} \mathrm{~min}^{-1}(10.2 \leq F F \leq 153)$ and $T=25^{\circ} \mathrm{C}$. b) Energy Efficiency $E E$ as a function of the average current density.

It clearly shows that changing the average current density shifts the voltage curves up in charge and down in discharge. The curves are approximately regularly spaced, which confirms the resistive behavior of the battery. At $J \geq 90 \mathrm{~mA} \mathrm{~cm}^{-2}$, the end of charge is only dictated by the voltage cut-off at $1.5 \mathrm{~V}$ : if there was no risk of starting undesired second reactions at high voltage, it would be logical to expand the voltage limits accordingly to the operating current. As it was often reported in the literature, by Chen et al. [13] for instance, cycling at higher current with maintained voltage boundaries shortens the accessed capacity. The variation of the energy efficiency is linear and drops with increasing current density. It reduces by almost $40 \%$ between the minimum and maximum operating current: this important influence relates to the ohmic drop exacerbated at high current and counting twice, both during charge and discharge. The internal cell operation is represented by means of the local capacity percentage $Q_{k}^{*}$ and the standard deviation of local currents $\sigma_{j}^{*}$ in Figure 7. 

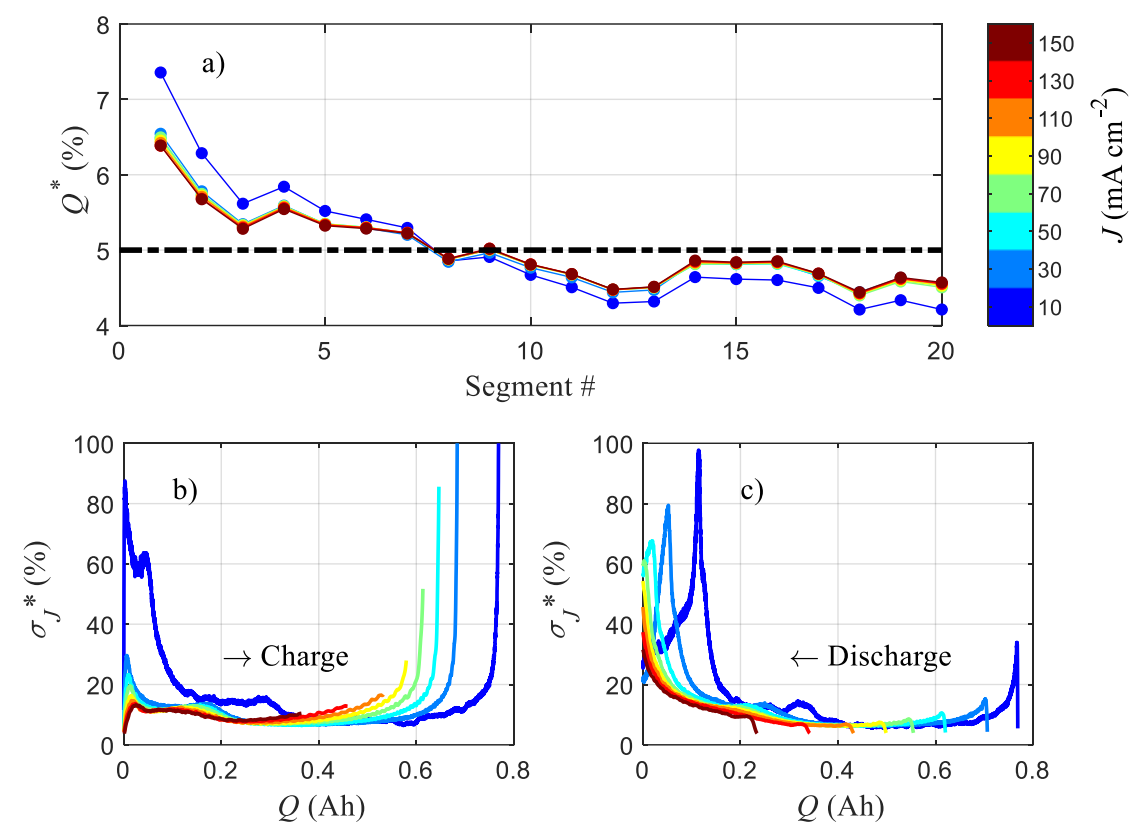

Figure 7. Effect of the average current density on a) the percentage of the total capacity for each segment in charge, and on the variation of $\sigma_{j}^{*}$ versus the capacity during charge b) and during discharge c). $\dot{q}=100 \mathrm{~mL} \mathrm{~min}^{-1}(10.2 \leq F F \leq 153)$ and $T=25^{\circ} \mathrm{C}$.

As it is shown in Figure 7a, the capacity distribution along the cell is almost independent on the average current density. The capacity of the first two segments stand out at 6 and $7 \%$, while the others lie between 4.5 and 5.5\%. The heterogeneity in discharge (not presented here) is slightly larger, where a minimum appears around $100 \mathrm{~mA} \mathrm{~cm}^{-2}$. This observation on capacity is actually a direct consequence of the heterogeneity of the local currents. The corresponding standard deviations are given for all currents in Figures $7 \mathrm{~b}$ and $7 \mathrm{c}$. The detailed evolution of $\sigma_{j}^{*}$ is complex. At the start and end of charge (Figure 7b), two areas of high heterogeneity are emphasized. The early spike (at low $Q$ ) is of high magnitude at small current but is almost absent above $70 \mathrm{~mA} \mathrm{~cm}{ }^{-2}$. The appearance of a second distinct spike only at $10 \mathrm{~mA} \mathrm{~cm}$ seems $^{-2}$ to be correlated to the subsidiary reaction observed in the anolyte after aging, as already mentioned (Figure 1). During the rest of the stage, the standard deviation remains below 20\%, before rising vertically at the end of charge for the low currents. This is reminiscent of the voltage curve whose inflection at the end is only noticeable for those currents (Figure 6). This time, $\sigma_{j}^{*}$ increase is correlated to a reactant depletion, which is not attained at high current since the voltage cut-off prevents it. In discharge (Figure 7c), all curves follow the same trend. For the three lowest current inputs, a small spike is visible at the start of discharge (high $Q$ in discharge), similar to the occurrence in the respective charge curves. The end of discharge outlines a rise of the deviation, more pronounced at low $J$. For $J \leq 50 \mathrm{~mA} \mathrm{~cm}{ }^{-2}$, this rise is followed by a peculiar diminution of $\sigma_{j}^{*}$ for the last percent of discharge (e.g. $Q$ less than 0.1 $\mathrm{Ah}$ at $10 \mathrm{~mA} \mathrm{~cm}^{-2}$ ). This singularity relates to the anolyte subsidiary reaction that caused a double spike early in charge at lowest $J$; this substantiates that this reaction is reversible.

Influence of the flow rate. The flow rate is an important parameter in the RFB operation as it modifies the energy efficiency of the cell and of the system. It was investigated by many authors from the flow field [18] to the fiber scale [19] in order to quantify the influence of the active 
species transport and diffusion on the overvoltages [20]. The average current density and the temperature being maintained at their standard value, the flow rate of both electrolytes was varied. The cell voltage versus capacity curves are plotted in Figure 8a. Their modification relative to flow rate is completely different than with current in Figure 6. The voltage plots keep essentially the same shape for any $\dot{q}$, only the accessed capacity is modified accordingly.
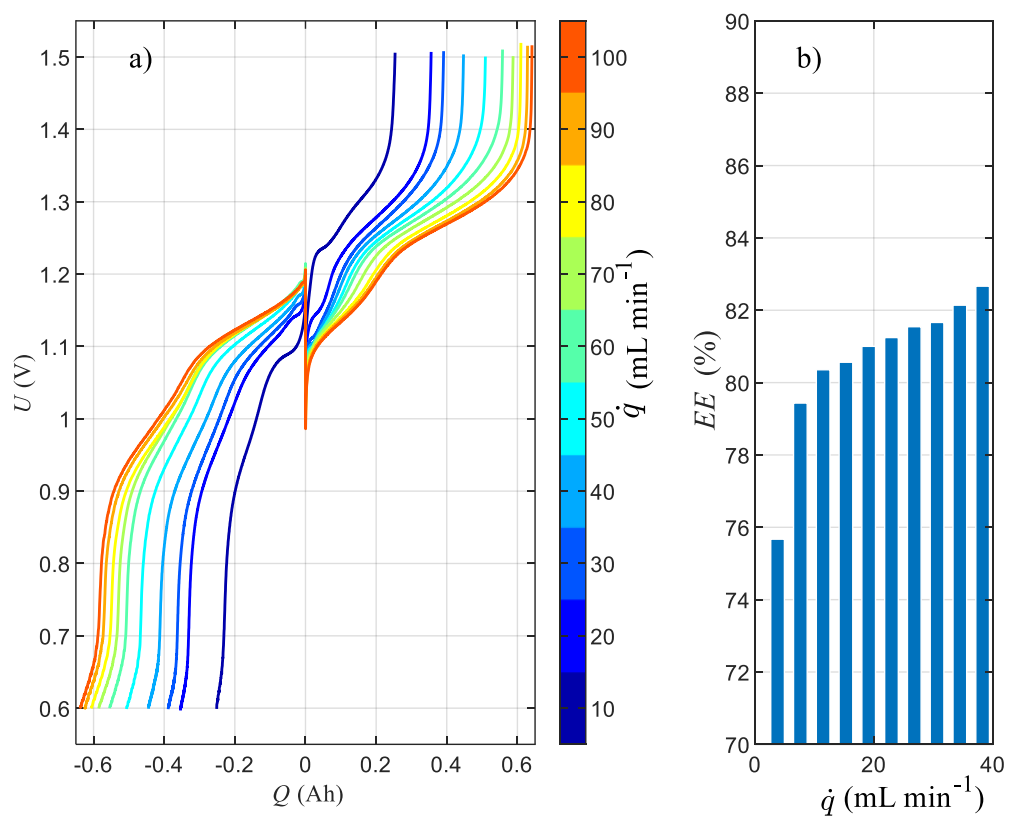

Figure 8. a) Voltage charge and discharge curves versus capacity for all the flow rates tested, $J=40 \mathrm{~mA} \mathrm{~cm}{ }^{-2}$ and $T=25^{\circ} \mathrm{C}$. The flow factor is $3.8 \leq F F \leq 38.4$. b) Energy Efficiency $E E$ as a function of the flow rate.

It means that the limiting processes are independent on $\dot{q}$, their occurrence is just delayed with enhanced transport of species. It is rationalized by the concentration overpotential included in the cell voltage: this term rises faster during operation at reduced flow rate, thus limiting the time of charge and discharge phase. Consequently, the capacity accessible increases with flow rate. According to the model of Chen et al. [21], the experiments of You et al. [19] and of Milshtein et al. [22], this phenomena is also explained by the bulk supply of active species and by the mass transfer coefficient variations with the flow rate. Nemani and Smith [16] emphasized the effect of the flow rate on the through plane reaction distribution, showing that regions of low reaction rate appear at low flow rate leading to high polarization losses.

The polarization effect of the flow rate is also illustrated by the cycle efficiency $E E$. As presented in Figure 8b, it equals $76 \%$ at the lowest flow rate, and increases from $80 \%$ to $83 \%$ between 30 and $100 \mathrm{~mL} \mathrm{~min}{ }^{-1}$. Alongside global effects, the influence of flow rate is even more pronounced on internal homogeneity. Figure 9a proves that accessing more capacity (made possible at high $\dot{q}$ ) is compatible with improved homogeneity, which is different from the effect of current. Indeed, the slowest electrolyte flow induces a variation of local capacity between $3 \%$ and $11 \%$ of the total capacity, while the distribution is confined between $4 \%$ and $7 \%$ at highest flow input. By comparing the variation of local capacity in absolute value (Ah), it comes that rising the electrolyte flow rate from 10 to $100 \mathrm{~mL} \mathrm{~min}^{-1}$ boosts the production of charges at the outer segments by $75 \%$ (and only by $33 \%$ at the first ones): the outlet logically suffers first of reactant insufficient supply. Flow rate has a conspicuous impact over the uniformity of the cell operation. This is also in accordance with the trend of the numerical results of Nemani 
and Smith [16]. The influence of $\dot{q}$ is slightly more pronounced in charge than in discharge, which means that the discharging step is more critical in terms of internal homogeneity.
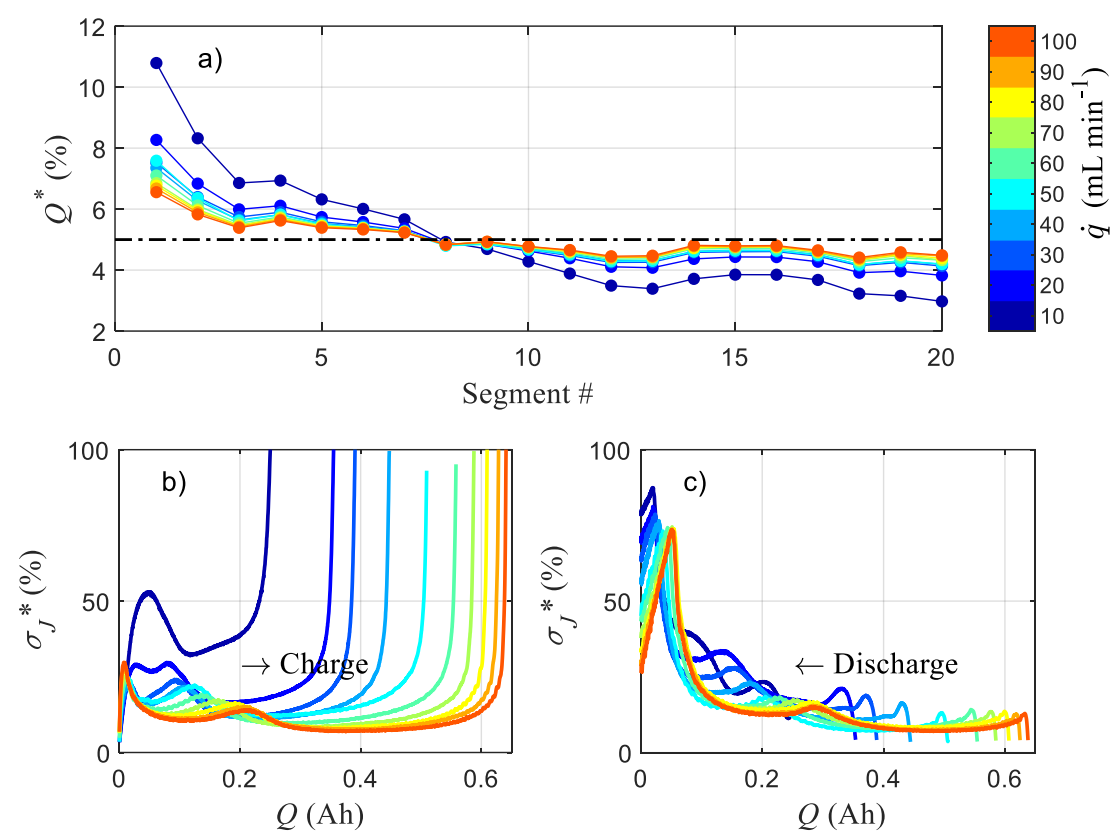

Figure 9. Effect of the flow rate on a) the percentage of the total capacity for each segment in charge, and on the variation of $\sigma_{j}^{*}$ versus the capacity during charge b) and during discharge c). $J=40 \mathrm{~mA} \mathrm{~cm}^{-2}$ and $T=25^{\circ} \mathrm{C}$. The flow factor is $3.8 \leq F F \leq 38.4$.

Figure $9 \mathrm{~b}$ and $9 \mathrm{c}$ display the homogeneity of internal currents versus the capacity in charge and discharge, for all the tested flow rates. The consequence of $\dot{q}$ on instantaneous internal homogeneity is visible throughout the step, while in the current study (Figures $7 \mathrm{~b}$ and $7 \mathrm{c}$ ), $\sigma_{j}^{*}$ predominantly changed at start of charge and end of discharge.

In charge, three parts can be distinguished. Before $2 \%$ of charge, a first spike appears whose magnitude and position are determined by the flow rate: the faster the electrolyte flow, the earlier and higher the spike. After $2 \%$ of charge, a second spike occurs between $0.1 \mathrm{Ah}$ and $0.25 \mathrm{Ah}$ (depending on $\dot{q}$ ) whose magnitude decreases as the flow rate increases. It appears later as the flow rate increases. At $20 \mathrm{~mL} \mathrm{~min}^{-1}$ and then $10 \mathrm{~mL} \mathrm{~min}^{-1}$, the two spikes end up merging into a conspicuous wave. After these initial disturbances, the internal distribution recovers homogeneity for a duration depending on $\dot{q}$. The end of charge matches with a rapid increase of $\sigma_{j}^{*}$ up to $100 \%$. In discharge, all curves in Figure 9c exhibit a humped shape at start, which is larger and higher at decreased $\dot{q}$ value. A second wave is visible later in discharge (and corresponds to the subsidiary anolyte reaction observed in the voltage profiles in Figure 1). It precedes the inflection caused by active species depletion at the end of discharge. The last $10 \%$ of discharge features a new decrease of $\sigma_{j}^{*}$ as already observed in the study of the current.

This last region is more prominent at higher flow rate, revealing that more species of this anolyte form can react thanks to a mitigated concentration overpotential. The standard deviation profiles convey the idea that flow rate could be optimized during each phase while maintaining local current uniformity. The graphs will help to define a threshold where the flow rate needs to be adjusted according to the SoC of the battery. The analysis can be narrowed-down by keeping the SoC constant. This is what the polarization curves aim for. They uncover the real 
influence of the operating parameters on the cell resistance and on the local current uniformity. Polarization Curves were performed at each flow rate. The global and the local PCs obtained at SoC 50\% are given in Figure 10. For better reading only the PC of Seg\#1 (dots) and Seg\#20 (solid lines) are given, the PCs of the other segments being in between. For simplification in the following text they are noted PC\#1 or PC\#20.
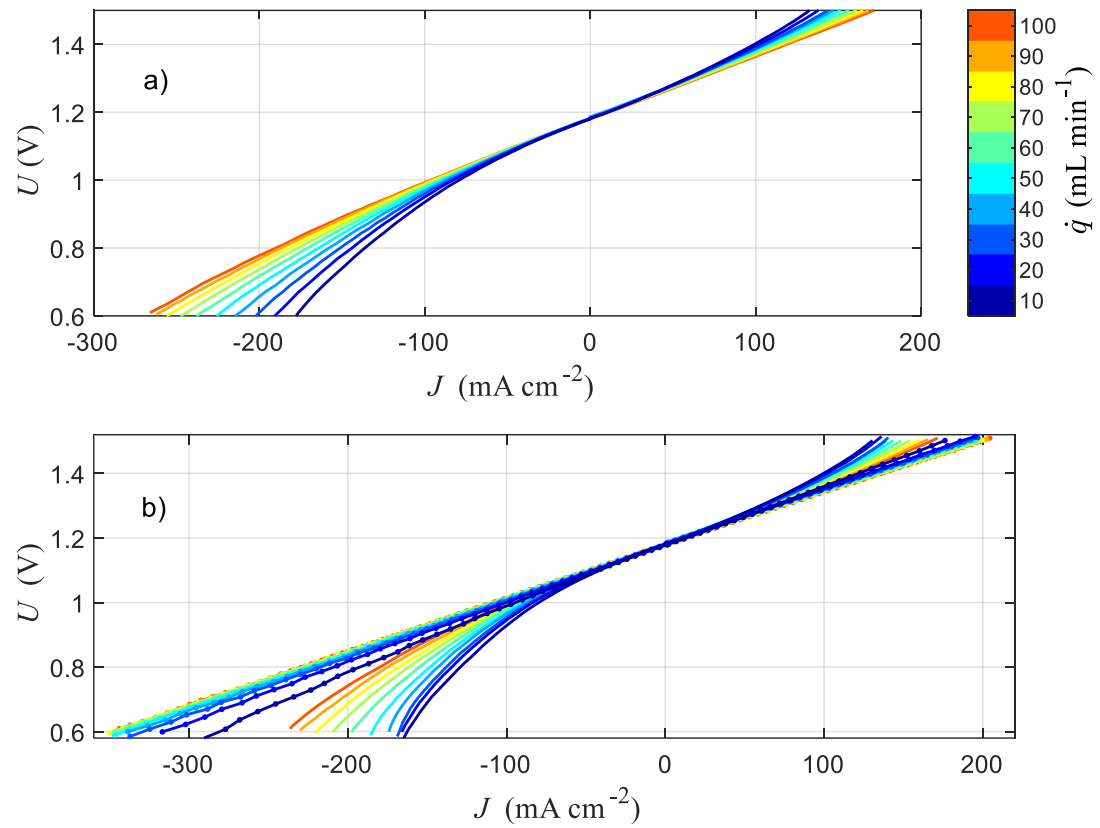

Figure 10. Polarization Curves at SoC $50 \%$ for all flow rates tested. a) Global PC and b) local PCs of Seg\#1 (dots) and Seg\#20 (solid lines), $T=25^{\circ} \mathrm{C}$.

The global PCs outline a large effect of the flow rate and an unequal response in charge and discharge: the voltage drop observed in charge is lower than the voltage drop observed in discharge at the same current. Milshtein and coworkers [22] evidenced the same trend by modelling and experiments, showing that discharge generates more serious mass transport limitation that conveys higher overpotential at a given operating current.

Figure 10 shows that PC\#1 (cell inlet) exhibits a linear characteristic at any flow rate, while PC\#20 is not straight throughout the range of currents scanned. PC\#1 and PC\#20 overlap around $J=0$, and within a narrow current window that depends on the flow rate. Indeed, the deviation of PC\#20 from linearity starts from a lower current as the flow rate is decreased. Such a distortion towards high currents derives from the reactant depletion emerging along the length of the cell, closer to the inlet as flow rate is reduced. This limitation is never observed for Seg\#1. To get a clearer view of PC\#1 evolution with flow rate, a linear regression is performed within the current window $-200 \leq J \leq 200 \mathrm{~mA} \mathrm{~cm}^{-2}$ to get the most accurate fit. Starting from 1.95 $\Omega \mathrm{cm}^{2}$ at the lowest flow rate, the resistance shows a decreasing trend with flow rate, with a total reduction of $15 \%$ at $100 \mathrm{~mL} \mathrm{~min}^{-1}\left(\mathrm{R}_{\mathrm{PC} \# 1}=1.65 \Omega \mathrm{cm}^{2}\right)$. The evolution is mostly marked between 10 and $30 \mathrm{~mL} \mathrm{~min}^{-1}$. Even though PC\#1 is visually linear whatever the flow rate, the segment resistance is still affected by reactant supply. This could be related to the spatial expanse of the segments showing that the effect of the concentration variation appears early in the cell. 
Similarly to the cycling analysis, the local current distribution can be observed through its standard deviation $\sigma_{j}$ during a PC. It is however chosen to represent it in absolute value $\left(\mathrm{mA} \mathrm{cm}^{-2}\right)$ rather than in $\%$ of the total $J$, because it would not be calculable around $J=0$.

Figure 11 illustrates $\sigma_{j}$ for global PCs at the three flow rates 10,50 and $100 \mathrm{~mL} \mathrm{~min}^{-1}$. The subplots correspond to the SoC $20 \%, 50 \%$ and $80 \%$. The black solid lines represent a local current deviation threshold of $10 \%$ of the average current density $J$.
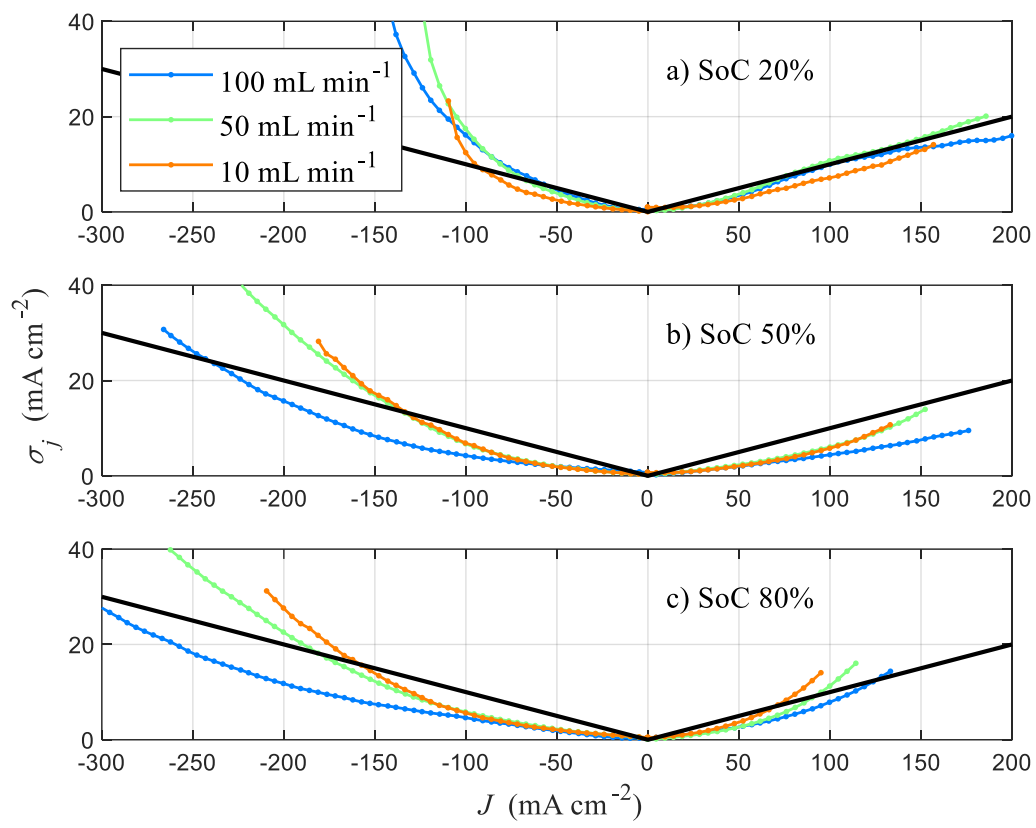

Figure 11. Variation of $\sigma_{j}$ during Polarization Curves at 10,50 and $100 \mathrm{~mL} \mathrm{~min}^{-1}$. a) $\mathrm{SoC}=20 \%$, b) $\mathrm{SoC}=50 \%$ and c) $\mathrm{SoC}=80 \%$. The black solid line represents the limit of $\sigma_{j}=10 \%$ of the applied current $J$.

At SoC $50 \%$, the curves display a more important deviation in discharge than in charge, in particular at low $\dot{q}$. This confirms the findings from the PCs in Figure 10: discharge yields more mass transport limitation in comparison to charge. Additionally, $\sigma_{j}$ exceeds the $10 \%$ threshold much earlier at low flow rate. As already evidenced with the cycling analysis, the standard deviation of local current is directly linked to reactant supply: the slower advective flow, the more concentration gradient between the inlet and outlet segments and therefore the more internal current heterogeneity. Yet it should be noted that the standard deviations for the three flow rates match exactly within the current range of $-60 \leq J \leq 60 \mathrm{~mA} \mathrm{~cm}^{-2}$.

The effect of SoC on $\sigma_{j}$ is clearly visible. At SoC $20 \%$ in charge - respectively at SoC $80 \%$ in discharge - a good uniformity can be maintained for an extended range of currents, whereas the discharge - respectively the charge - entails a deviation above $10 \%$ at low average current density. Nevertheless, the results at SoC $20 \%$ and $80 \%$ are not perfectly symmetrical.

At SoC $20 \%$ in discharge, the influence of flow rate on $\sigma_{j}$ is insignificant. The low concentration of reactant outweighs the impact of electrolyte flow by causing a rapid increase of $\sigma_{j}$ around the same current for all flow rates. The same phenomenon is visible to a lesser extent at SoC $80 \%$ in charge.

Influence of the temperature. The third parameter of study is the temperature, which can be modified thanks to the thermal control of the segmented device. A new temperature value was 
regulated three hours before starting the cycling, to make sure that the system stabilized to the desired temperature. In addition to the standard temperature of $25^{\circ} \mathrm{C}$, the tested values go from $10^{\circ} \mathrm{C}$ to $40^{\circ} \mathrm{C}$ by steps of $10^{\circ} \mathrm{C}$. The other parameters were kept to their standard value. It needs to be specified that the temperature study was performed on a new segmented set-up with similar materials and freshly prepared electrolytes, for convenience. This explains the disparate results with the other parameter studies in terms of capacity, because the anolyte was not at the same state of aging. The cell showed good stability at all temperatures and the capacity was recovered after the temperature study, excluding any irreversible degradation (such as material precipitation). However, further testing steps should be carried out, as problems might appear at temperatures above $40^{\circ} \mathrm{C}$ or over extended cycling.
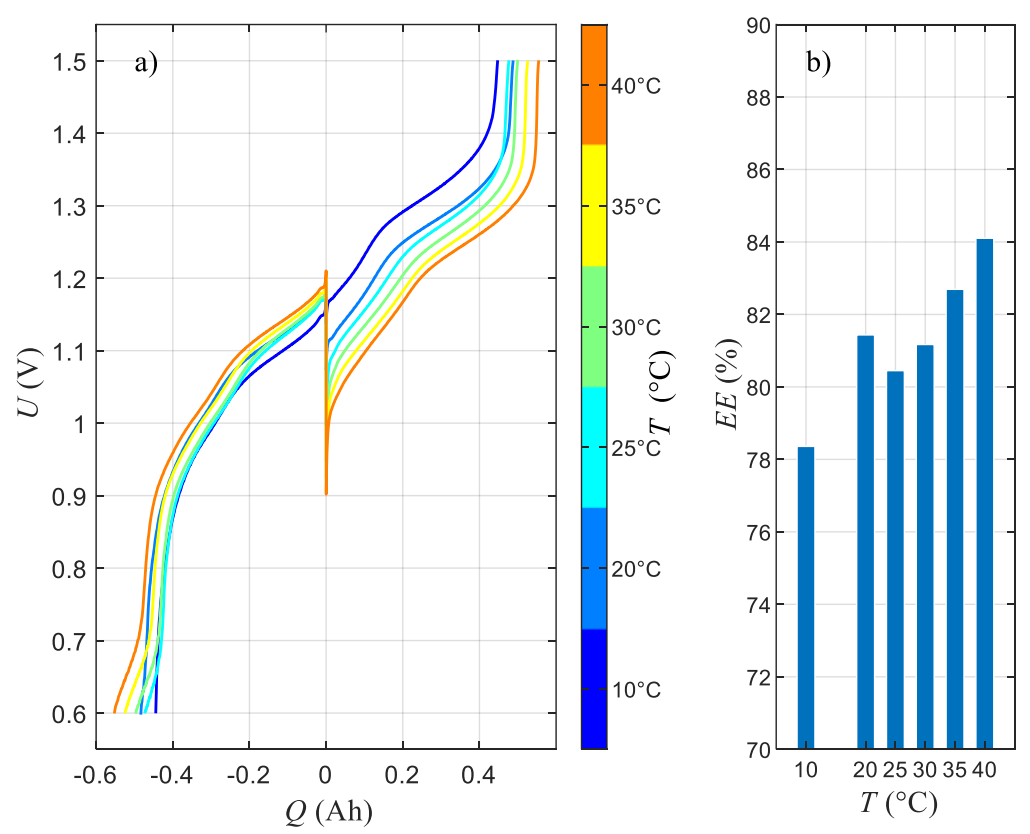

Figure 12. a) Voltage charge and discharge curves as a function of the capacity for the temperature values tested, $J=40 \mathrm{~mA} \mathrm{~cm}^{-2}$ and $\dot{q}=100 \mathrm{~mL} \mathrm{~min}^{-1}$. b) Energy Efficiency $E E$ as a function of the temperature.

Figure 12a displays the voltage curves versus capacity at all temperature values, along with the energy efficiency versus temperature. One striking conclusion is the discrepancy between the temperature effect on charge and discharge profiles: the charging curves are shifted upwards at lower $T$, while the discharge curves all overlap. Their only difference is the low voltage plateau close to the end of the stage. This part is only accessible at temperatures above $25^{\circ} \mathrm{C}$. This results in a higher capacity available as the temperature increases, from $450 \mathrm{mAh}$ at $10^{\circ} \mathrm{C}$ to $560 \mathrm{mAh}$ at $40^{\circ} \mathrm{C}$. Many parameters are temperature dependent and can modify the battery performance. It was measured that the temperature significantly affected the viscosity of the electrolytes: from $7 \mathrm{mPa} s$ at $20^{\circ} \mathrm{C}$ for the catholyte to $2 \mathrm{mPa} \mathrm{s}$ at $40^{\circ} \mathrm{C}$, and from $10 \mathrm{mPa} \mathrm{s}$ $\left(20^{\circ} \mathrm{C}\right)$ to $4 \mathrm{mPa} \mathrm{s}\left(40^{\circ} \mathrm{C}\right)$ for the anolyte.

Moreover, it is well-known that temperature has an activation effect on physico-chemical processes, such as the reaction rates or transport of species through the membrane, described by an Arrhenius law [23]. Consequently, the overall battery process is less resistive at high temperature, making the accessible capacity higher as observed in Figure 12a. In a similar way, the energy efficiency increases regularly with the temperature (Figure 12b). 
On the other hand, elevated temperature can have detrimental impact on the battery. In this study, it was observed that an elevated temperature amplified water osmosis through the membrane, which modifies the electrolyte concentration. In a VFB, vanadium ions used on the negative side precipitate when the temperature drops, while solubility issues occur at elevated temperature in the catholyte [23].
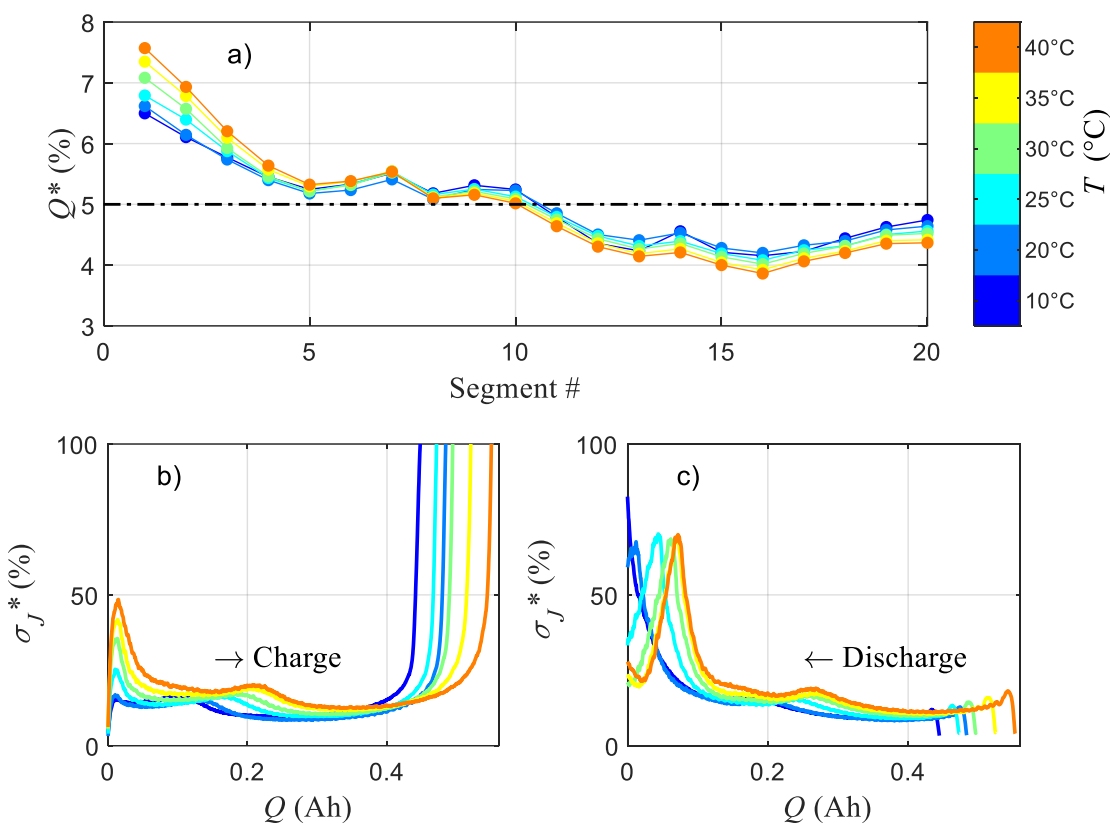

Figure 13. Effect of the temperature on a) the percentage of the total capacity for each segment in charge, and on the variation of $\sigma_{j}^{*}$ versus the capacity during charge b) and during discharge c). $J=$ $40 \mathrm{~mA} \mathrm{~cm}{ }^{-2}$ and $\dot{q}=100 \mathrm{~mL} \mathrm{~min}^{-1}$.

The temperature influence is also assessed on the internal features of the cell. In Figure 13a, the percentage of the local charging capacity is represented for the several temperatures. The inlet segments show an increase of their capacity between $20^{\circ} \mathrm{C}$ and $40^{\circ} \mathrm{C}$. Seg \#1 gains $1 \%$ on the share of the total capacity, which is the most pronounced change. This occurs at the expense of cell homogeneity, which is compounded at elevated temperature. By looking closely at the local current deviation during charge in Figure 13b, it becomes clear that the temperature affects the first part of the charging phase. Indeed, the early spike rises regularly with $T$, confirming the degradation of homogeneity with heating. After the first $15 \%$ of charge, all profiles of $\sigma_{j}^{*}$ lie below $20 \%$ deviation. The heterogeneity steeply rises during the final percent of charge.

The profiles of $\sigma_{j}^{*}$ in discharge shown in Figure 13c reveal that the temperature has a limited effect on the current deviation for the major part of the discharge. At start of each discharge (on the right-hand side of the figure), the initial spike is slightly enlarged by a high $T$. At the end, the steep rise caused by reagent depletion is followed by a new decrease for temperatures above $20^{\circ} \mathrm{C}$. As already mentioned in the studies of $J$ and $\dot{q}$, this drop is associated with potential variation related to the subsidiary anolyte reaction. 

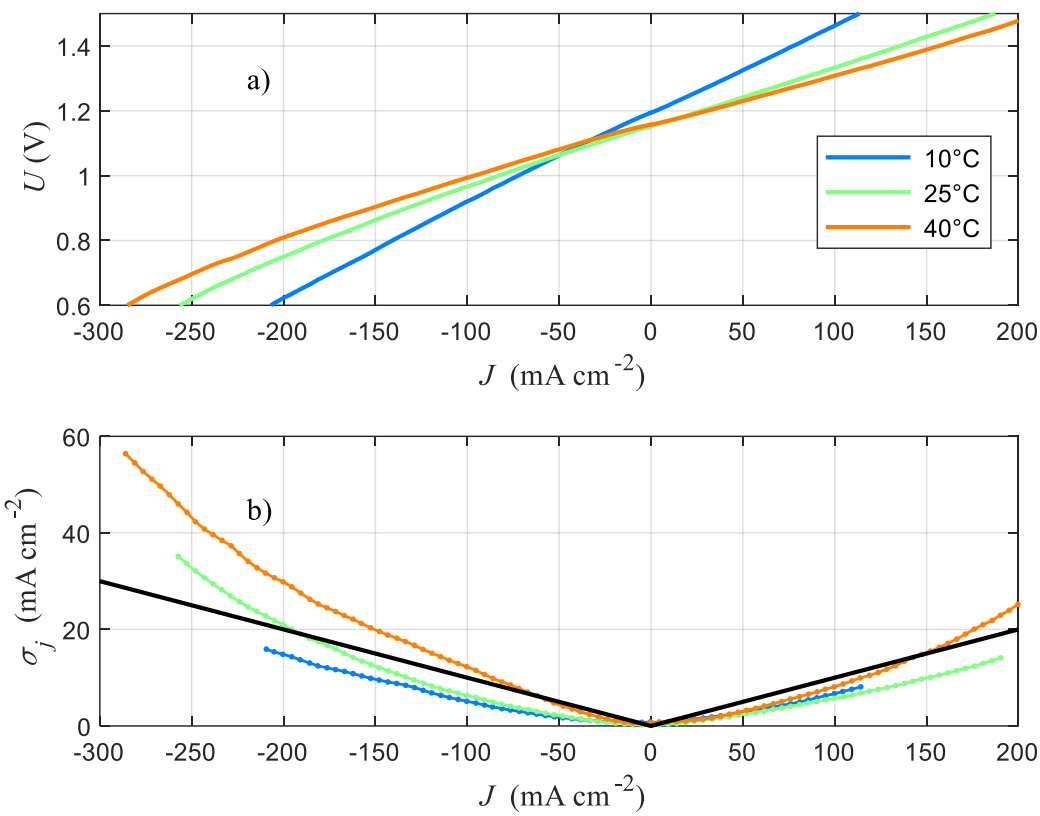

Figure 14. a) Global Polarization Curves for the three temperatures: $10^{\circ} \mathrm{C}, 25^{\circ} \mathrm{C}$ and $40^{\circ} \mathrm{C}$. b) Variation of $\sigma_{j}$ during the PCs. The black solid line represents the limit of $\sigma_{j}=10 \%$ of the applied current $J$. SoC $50 \%$ and $\dot{q}=100 \mathrm{~mL} \min ^{-1}$.

Figure 14a presents the global PCs at SoC $50 \%$ measured at $10^{\circ} \mathrm{C}, 25^{\circ} \mathrm{C}$ and $40^{\circ} \mathrm{C}$. Between -150 and $150 \mathrm{~mA} \mathrm{~cm}^{-2}$, the PCs are linear and their slope show that the low $T$ unambiguously hampers the cell performance with a high equivalent cell resistance, while the highest $T$ slightly enhances it. In the meantime, the coldest condition provides the most linear PC through the full current range. The local current standard deviation $\sigma_{j}$ during PC presented in Figure 14b provides complementary information. It clearly highlights that a higher temperature drives more heterogeneity. This confirms the trend detected in the cycling analysis in Figure 14a: elevated temperature boosts the reactions at the inlet and generates an uneven current distribution. At $40^{\circ} \mathrm{C}$, the heterogeneity cannot be kept under the $10 \%$ limit during discharge, whereas the maximum charging current to comply with the threshold is around $150 \mathrm{~mA} \mathrm{~cm}$. The lowest $T$ leads to good cell uniformity, at the cost of low cell performance.

Comparison of the impact of the three parameters. It can be observed from the results that the highest current density $J=150 \mathrm{~mA} \mathrm{~cm}^{-2}$ (at $100 \mathrm{~mL} \mathrm{~min}^{-1}$ ) and lowest flow rate tested $\dot{q}=10 \mathrm{~mL} \mathrm{~min}^{-1}$ (at $40 \mathrm{~mA} \mathrm{~cm}{ }^{-2}$ ) give access to a similar cycling capacity of about $200 \mathrm{mAh}$ with very different voltage profiles, as shown in Figure 15. This enables the comparison of these two extreme duty points. 


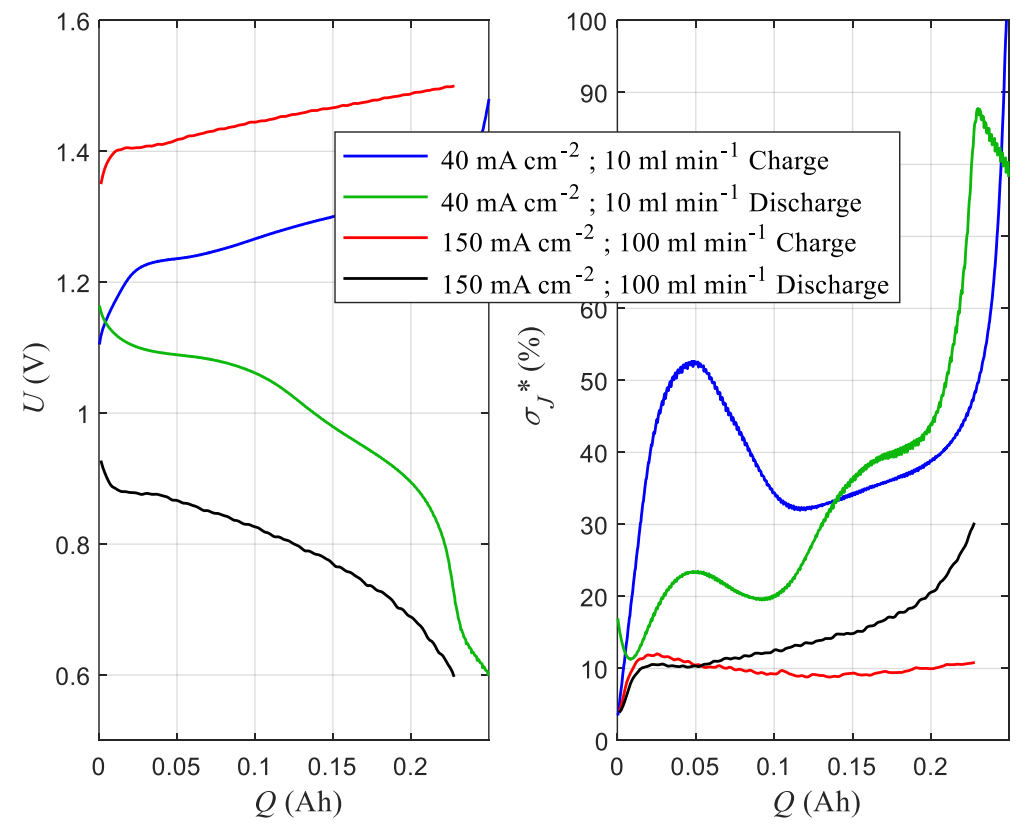

Figure 15. Cell voltage during cycling a) and on the variation of $\sigma_{j}^{*}$ b) measured for two sets of operating parameters: $J=40 \mathrm{~mA} \mathrm{~cm}{ }^{-2}$ and $\dot{q}=10 \mathrm{~mL} \mathrm{~min}^{-1}$ and $J=150 \mathrm{~mA} \mathrm{~cm}^{-2}$ and $\dot{q}=100 \mathrm{~mL} \mathrm{~min}^{-1}$.

Table II presents the features of these two cycles: their energy efficiency, the average current uniformity represented by $\bar{\sigma}_{j}^{*}$ the average over time of the standard deviation during charge or discharge as well as their respective advantages. This comparison exemplifies that a similar global metrics (here the accessed capacity) can actually hide very divergent cell operations.

Table II. Comparison of the features of two extreme duty cycles giving access to an equivalent capacity $(200-250 \mathrm{mAh})$

Extreme operating point Energy Efficiency Current dispersion Advantage

\begin{tabular}{llll}
\hline$J=150 \mathrm{~mA} \mathrm{~cm}^{-2}$ & \multirow{2}{*}{$55 \%$} & $\begin{array}{l}10 \% \text { in charge } \\
14 \% \text { in discharge }\end{array}$ & Fast charge \\
\hline $\begin{array}{l}\dot{q}=100 \mathrm{~mL} \mathrm{~min}^{-1} \\
J=40 \mathrm{~mA} \mathrm{~cm}^{-2}\end{array}$ & \multirow{2}{*}{$75 \%$} & $\begin{array}{l}40 \% \text { in charge } \\
\dot{q}=10 \mathrm{~mL} \mathrm{~min}^{-1}\end{array}$ & $\begin{array}{l}35 \% \text { in discharge } \\
\text { Low pump consumption }\end{array}$ \\
\hline
\end{tabular}

Cycling at high current impairs the cell efficiency but maintains acceptable local current uniformity. Contrarily, a low flow rate is detrimental for the homogeneity of the cell but features better efficiency than high current. In the meantime, pump consumption is mitigated by slow electrolyte flow input, but also by fast charge (provided that the pumps are switched off after full charge). Preferring one duty point over the other is disputable and depends on the criteria taken into consideration. Both operational conditions affect the pump consumption to a certain extent. This must also be regarded when assessing the total efficiency of the system. 


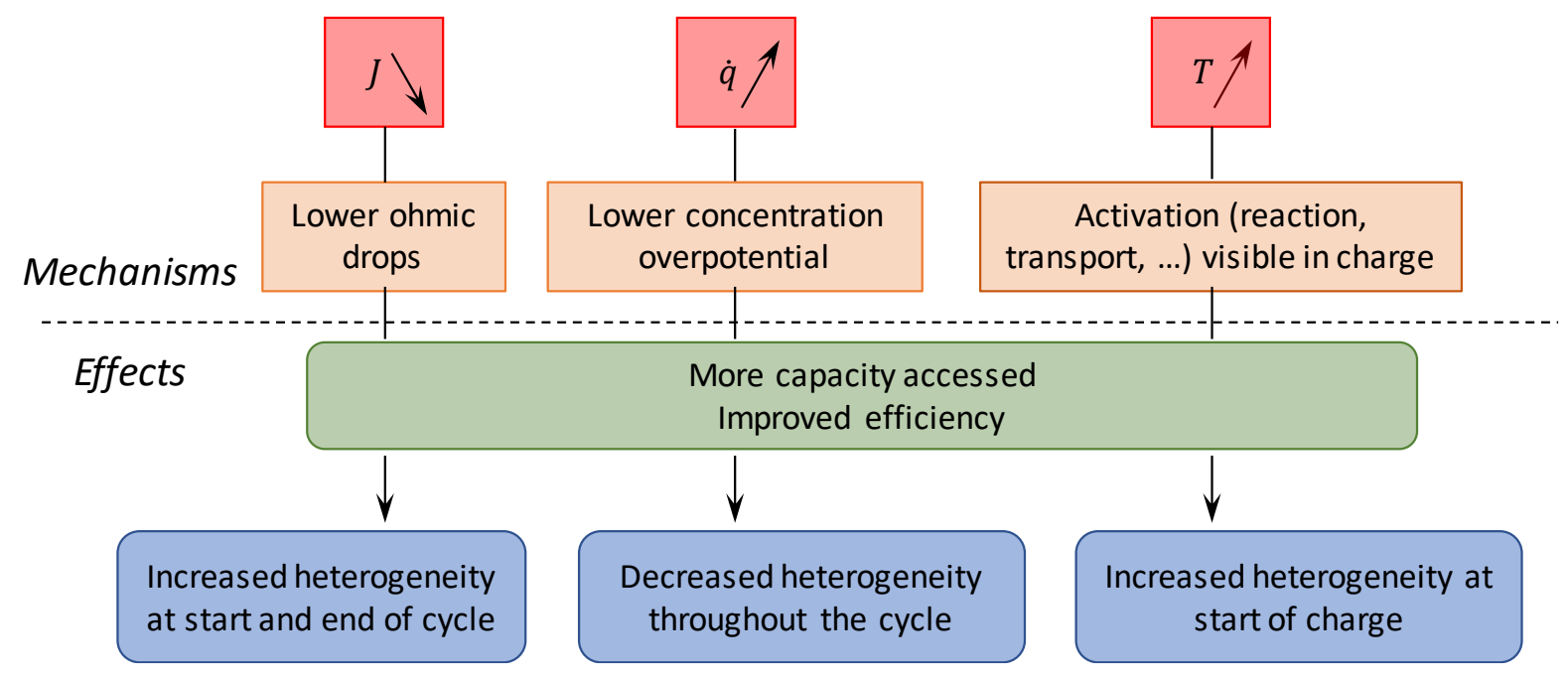

Figure 16. Effects of the average current density, the flow rate and the temperature on the global and local cell performances.

The parameter study results (presented in Figures 6,8 and 12) have been gathered into the diagram in Figure 16, to generalize how the variation of each parameter impacts the cell performance. Either diminishing the average current density, or rising the electrolyte flow rate or increasing the temperature, yield the same global effects: they give access to more capacity and improve energy efficiency.

The influence of the flow rate on the energy efficiency is nevertheless intricate as it can be evaluated both at the cell scale and at the system scale. At the cell scale, the energy efficiency (Figure $8 \mathrm{~b}$ ) increased by $6 \%$ between 10 and $100 \mathrm{~mL} \mathrm{~min}^{-1}$. This variation can be related to the reduction of the internal heterogeneity of the current distribution (Figure 9a). The flow rate mainly influences the accessed capacity which strongly increases at faster flow. On the other hand, by considering the whole system including the pumps, the global energy efficiency is lower at high flow rate as the pumps consumption rises.

In this work, it was proven that the specific lever mechanism of the three parameters of study (flow rate, current and temperature) implied dissimilar consequences at local scale. High electrolyte flow rate makes the current distribution more uniform throughout the cycle. A low current or an elevated temperature maintain a good homogeneity for the most part of the cycle. They however change the SoC window on which the cell is cycled, and with it the local current heterogeneity at start and end of each phase. Through specific lever mechanisms, changing $J$ or $\dot{q}$ or $T$ drives a particular modification of the internal operation of the battery and the global standard metrics are not sufficient to depict the real consequences.

\section{Conclusions}

An internal investigation with a specific set-up such as the segmented cell used in this study is crucial to comprehend the system sensitivity to operational conditions. Moreover, the best operating point does not exist and it results in trade-offs that must be appraised accordingly to the flow battery technology.

The parameter study substantiates that all current, flow rate and temperature factors dictate differently the global cell performance along with the internal current distribution. 
The evolution of the standard deviation of local currents with time during a step of cycling is a relevant variable to examine. It exhibits several distinct zones:

- At the very start of charge, a first spike appears. It is exacerbated at low current, high flow rate, or high temperature.

- At the end of charge, the steep increase of the deviation correlates with the voltage rise; it is attributed to reactant starvation.

- In discharge, $\sigma_{j}^{*}$ also features an early hump enlarged by a small current input, a low flow rate or an increased temperature. The discharge ends with a stark rise of current deviation. In the conditions that give access to the low potential plateau, the deviation falls back down during the last percent of discharge.

Operational challenges arise from this parameter study:

- The operating conditions alter the SoC window accessed during cycling. Consequently, it is difficult to compare the voltage or $\sigma_{j}^{*}$ curves for several parameter values, since the battery SoC is also modified. The effects of the parameter value and the SoC cannot be entirely isolated. In particular, the early spike of current deviation in charge is most critical at lowest current and highest temperature. It can stem from a very low initial SoC (because the cell is more deeply discharged in these two extreme conditions) or can be caused by the extreme parameter values themselves.

- The voltage curves as well as the current deviation curves are distorted by the convoluted anolyte characteristics. A spike arises in the middle of the charge or discharge phase and a plateau of additional capacity can be reached at the end of discharge, under propitious conditions (e.g. low current or high T). These particularities sometimes complicate the results analysis.

The results of this parameter study also suggest new ways of optimizing the system to prevent critical internal heterogeneity and in the meantime save pump power consumptions. The cycling strategies stemming from the present conclusions will be examined and tested in a further paper.

\section{References}

[1] M. Cazot, G. Maranzana, J. Dillet, F. Beille, T. Godet-Bar and S. Didierjean, "Symmetric-cell characterization of the redox flow battery system: Application to the detection of degradations," Electrochimica Acta, vol. 321, p. 134705, 2019.

[2] Q. Chen, M. R. Gerhardt and M. J. Aziz, "Dissection of the Voltage Losses of an Acidic Quinone Redox Flow Battery," Journal of the Electrochemical Society, vol. 164, pp. A1126A1132, 2017.

[3] Y. A. Gandomi, D. S. Aaron, T. A. Zawodzinski and M. M. Mench, "In situ Potential Distribution Measurement and Validated Model for All-vanadium Redox Flow battery," Journal of the Electrochemical Society, vol. 163, pp. A5188-A5201, 2016.

[4] M. Cecchetti, A. Casalegno and M. Zago, "Local potential measurement through reference electrodes in vanadium redox flow batteries: Evaluation of overpotentails ans electrolytes imbalance," Journal of Power Sources, vol. 400, pp. 218-224, 2018. 
[5] A. Bhattarai, N. Wai, R. Schweiss, A. Whitehead, G. Scherer, P. Ghimire, T. D. Nguyen and H. H. Hng, "Study of flow behavior in all-vanadium redox flow battery using spatially resolved voltage distribution," Journal of Power Sources, vol. 360, pp. 443-452, 2017.

[6] P. C. Ghimire, A. Bhattarai, R. Schweiss, G. G. Scherer, N. Wai and Q. Yan, "A comprehensive study of electrode compression effects in all vanadium redox flow batteries including locally resolved measurements.," Applied Energy, vol. 230, pp. 974-982, 2018.

[7] Y. A. Gandomi, D. S. Aaron, J. R. Houser, M. C. Daugherty, J. T. Clement, A. M. Pezeshki, T. Y. Ertugrul, D. P. Moseley and M. M. Mench, "Critical review- Experimental Diagnostics and Material Characterization Techniques Used on Redox Flow Batteries.," Journal of the Electrochemical Society, vol. 165, pp. A970-A1010, 2018.

[8] R. Eckl, R. Grinzinger and W. Lehnert, "Current distribution mapping in polymer electrolyte fuel cell - A finite analysis measurement uncertainty imposed by lateral currents.," Journal of Power Sources, vol. 154, pp. 171-179, 2006.

[9] W. Y. Hsieh, C. H. Leu, C. H. Wu and Y. S. Chen, "Measurement of local current density of allvanadium redox flow batteries," Journal of Power Sources, vol. 271, pp. 247-251, 2014.

[10] J. T. Clement, D. Aaron and M. M. Mench, "In situ Localized Current Distribution Measurements in All-Vanadium Redox Flow Batteries," Journal of the Electrochemical Society, vol. 163, pp. A5220-A5228, 2016.

[11] G. Maranzana, O. Lottin, T. Colinart, S. Chupin and S. Didierjean, "A multi-instrumented polymer exchange membrane fuel cell: observation of the in-plane non-homogeneities," Journal of Power Sources, vol. 180, pp. 748-754, 2008.

[12] B. Yang, L. Hoober-Burkhardt, F. Wang, G. Prakash and S. Narayanan, "AN Inexpensive Aqueous Flow Battery for Large-Scale Electricity Energy Storage Based on Water-Soluble Organic Redox Couples," Journal of the Electrochemical Society, vol. 161, pp. 1371-1380, 2014.

[13] Q. Chen, L. Eisenach and M. Aziz, "Cycling Analysis of a Quinone Bromide Redox Flow Battery," Journal of the Electrochemical Society, vol. 163, pp. A5057-A5063, 2016.

[14] S. Zhang, X. Li and D. Chu, "An Organic Electroactive Material for Flow Batteries," Electrochimica Acta, vol. 190, p. 737-743, 2016.

[15] M. Goulet and M. J. Aziz, "Flow Battery Molecular Reactant Stability Determined by Symmetric Cell Cycling Methods," Journal of the Electrochemical Society, vol. 165, pp. A1466A1477, 2018.

[16] V. Nemani and K. Smith, "Uncovering the role of flow rate in redox-active polymer flow batteries: simulation of reaction distributions with simultaneous mixing in tanks," Electrochimica acta, vol. 247, pp. 475-485, 2017.

[17] M. Becker, N. Bredemeyer, N. Tenhumberg and T. Turek, "Polarization curve measurements combined with potential probe sensing for determining current density distribution in vanadium redox-flow batteries," Journal of power sources, vol. 307, pp. 826-833, 2016. 
[18] R. M. Darling and M. Perry, "The influence of Electrode and Channel Configurations on Flow Battery Performance," Journal of The Electrochemical Society, vol. 161, pp. A1381-A1387, 2014.

[19] X. You, Q. Ye and P. Cheng, "The Dependence of Mass Transfer Coefficient on the Electrolyte Velocity in Carbon Felt Electrodes: Determination and Validation," Journal of The Electrochemical Society, vol. 164, pp. E3386-E3394, 2017.

[20] C. N. Sun, F. M. Delnick, D. S. Aaron, A. B. Papandrew, M. M. Mench and T. A. Zawodzinski Jr., "Resolving Losses at the Negative Electrode in All-Vanadium Redox Flow Batteries Using Electrochemical Impedance Spectroscopy," Journal of The Electrochemical Society, vol. 161, pp. A981-A988, 2014.

[21] C. Chen, H. Yeoh and M. Chakrabarti, "An enhancement to Vynnycky's model for all-vanadium redox flow battery," Electrochimica Acta, vol. 120, pp. 167-179, 2014.

[22] J. D. Milshtein, K. M. Tenny, J. L. Barton, J. Drake, R. M. Darling and F. R. Brushett, "Quantifying Mass Transfer Rates in Redox Flow Batteries," Journal of the Electrochemical Society, vol. 164, pp. E3165-E3275, 2017.

[23] R. Badrinarayanan and J. Zhao, "Extended dynamic model for ion diffusion in all-vanadium redox flow battery including the effects of temperature and bulk electrolyte transfer," Journal of Power Sources, vol. 270, pp. 576-586, 2014. 